\title{
Evolution of the Efficiency of Divalent Cobalt and Copper Chelates Based on Isatin Derivatives and Thiosemicarbazide Ligands as Inhibitors for the Corrosion of Sabic Iron in Acidic Medium
}

Hoda A. El-Ghamry

Tanta University

Ahmed Fawzy ( $\nabla$ afsaad13@yahoo.com )

Umm Al-Qura University

Thoraya A. Farghaly

Umm Al-Qura University

Tahani M. Bawazeer

Umm Al-Qura University

Nada Alqarni

University of Bisha

Fatmah M. Alkhatib

Tanta University

Mohamed Gaber

Tanta University

\section{Research Article}

Keywords: Isatin, Thiosemicarbazide, Chelates, Inhibition, Sabic iron, Corrosion.

Posted Date: June 15th, 2021

DOI: https://doi.org/10.21203/rs.3.rs-620711/v1

License: (c) (i) This work is licensed under a Creative Commons Attribution 4.0 International License.

Read Full License 


\section{Abstract}

Divalent cobalt and copper chelates of the two ligands 1-(1-Ethoxycarbonylmethyl-2-oxoindolin-3-ylidene) thiosemicarbazide (EOIT) and 1-(1-Benzyl-2-oxoindolin-3-ylidene) thiosemicarbazide (BOIT) are the target compounds of the current study. Identification of the constitution and geometry of these compounds have been performed using the possible physicochemical and analytical instruments. Elemental analysis, molar conductance and thermal analysis assured the composition of the four chelates to be [Co(POIT) $\mathrm{Cl}] \cdot 1.5 \mathrm{H}_{2} \mathrm{O},[\mathrm{Cu}(\mathrm{POIT}) \mathrm{Cl}],\left[\mathrm{Co}(\mathrm{BOIT}) \mathrm{Cl}_{2}\left(\mathrm{H}_{2} \mathrm{O}\right)\right] \cdot 5 \mathrm{H}_{2} \mathrm{O}$ and [Cu(BOIT) $\left.\mathrm{Cl}\right] \cdot \mathrm{Cl}$ which was further confirmed by the measurement of mass spectra. The architecture arrangement of the ligand atoms around $\mathrm{Co}$ and $\mathrm{Cu}$ centers has been determined depending on the UV-Vis spectral measurements and calculation of $\mu_{\text {eff }}$ values assuring the copper compounds to be square plane whereas the cobalt complexes have tetrahedral or octahedral arrangements. These compounds were examined as corrosion inhibitors for the Sabic steel in $1.0 \mathrm{M} \mathrm{HCl}$ utilizing potentiodynamic polarization, electrochemical impedance spectroscopy, mass-loss method and scanning electron microscopy at fixed temperature of $298 \mathrm{~K}$. The acquired outcomes disclosed that the inhibition efficiencies (\% IEs) of the examined compounds were set to be dependent on both the concentrations and composition of the compounds. The examined compounds were set to have high \% IEs, which were interpreted by strong adsorption of the compounds' molecules on the iron surface and such adsorption was discovered to follow Langmuir adsorption isotherm. The investigational results obtained from all utilized techniques were set to be in a good accord with each other.

\section{Introduction}

Iron and its alloys have numerous applications in industry and machinery due to their excellent mechanical properties. They are subjected to corrosion phenomenon in various media [1-3]. Corrosion phenomenon is a naturally occurring process $[4,5]$, which causes a deterioration of significant properties in metals and alloys, weakening of buildings and machinery, corrosion of petroleum pipeline, etc. resulting in dangerous problems for the economy and safety. As an example, iron rust and its alloys is regarded as a serious industrial problem particularly in acidic media [6-8] because acidic media are widely utilized in numerous applications such as industrial cleaning, acid discaling, pickling of steels, petroleum processes, etc. Nevertheless, due to the attack of the acidic media, iron and steel vessels used in these applications are subjected to corrosion. Therefore, it is indispensable to preserve metals and alloys from the harmful effect of corrosion phenomenon in different environments [9].

There is incessant increase in the development of efficient, convenient and environmentally friendly inhibitors to minimize metals electro-dissolution and corrosion [10]. Over the years, plentiful reports have been published to evaluate organic compounds and the product of their combination with inorganic compounds as inhibitors for metallic materials corrosion. Heteroatoms containing systems, such as compounds containing nitrogen, sulphur, oxygen and $p$-electron systems have been extensively applied as inhibitors for metals corrosion. Former studies have disclosed that these organic substances are adsorbed on the metallic surfaces and hence inhibit corrosion [10-13]. So, these compounds protect the metals from 
the corrosive species immediately through formation of resistive layer on the metal surface, which guarantee high resistance to electron transfer reactions $[14,15]$. Corrosion inhibiting tendency of the inhibitor is extremely affected by molecular orbitals and electron densities surrounding the donor atoms of inhibitor molecules [16-19].

Over decades, thiosemicarbazides are evidenced to be effective intermediates for the development of so many pharmaceutical and bioactive materials and hence, they are applied expandly in medicinal chemistry. The vast number of heterocycles produced from thiosemicarbazides is related primarily to the fact that these compounds can display the characteristics of $N(1)-; N(2) ; N(1) ; N(4) ; N(2) ; N(4)-; N(1)$; $S$, $\mathrm{N}(2)$; S- and N(4),S-nucleophiles [20]. Among of these heterocycles are the thiosemicarbazones derivatives with isatin counterparts that have attracted the concern of the pharmacy world owing to their extensive range of biological features [21-23] and industrial application as corrosion inhibitors [24-28]. Moreover, thiosemicarbazones (TSCs) are termed significant ligands with interesting ligating characteristics owing to thione-thiol tautomerism, and therefore bind to metallic centers in monodentate, bidentate or bridging modes $[29,30]$. The capability of TSCs to form stable complexes with transition metal ions makes them as versatile pharmacophores [31,32] and anti-corrosive agents [33, 34].

As a consequence of all the previous reports, the structure of two isatin-thiosemicarbazone based ligands, abbreviated by EOIT and BOIT, motivated us to be used as chelating agent for the synthesis of Co(II) and $\mathrm{Ni}(\mathrm{II})$ complexes with extensive insight into their corrosion inhibition for Sabic iron in $1.0 \mathrm{M} \mathrm{HCl}$ solutions utilizing alternative methods including potentiodynamic polarization (PDP), electrochemical impedance spectroscopy (EIS), mass-loss (ML) and scanning electron microscopy (SEM). Full structure identification of the synthesized compounds has been performed in a trial to study the structure-activity relationship.

\section{Experimental}

\subsection{Chemicals and methods}

All chemicals applied in the current study and solvents were purchased from Sigma-Aldrich, Merck and/ or across companies in Japan and used as received. The applicable corrosive medium $(1.0 \mathrm{M} \mathrm{HCl})$ which prepared by attenuation of $\mathrm{HCl}(37 \%)$ via bi distilled water. Solutions of the investigated compounds (inhibitors) were prepared using the organic solvent DMF and their concentrations range used was: 100 to $400 \mathrm{mg} / \mathrm{l}$. Corrosion experiments were conveyed out on Sabic iron specimens (SABIC Company, Saudi Arabia) with the composition (wt. \%): $0.076 \mathrm{C}, 0.125 \mathrm{Mn}, 0.0126 \mathrm{Cr}, 0.034 \mathrm{Cu}, 0.012 \mathrm{Si}, 0.008 \mathrm{~S}, 0.009 \mathrm{P}$, $0.003 \mathrm{Mo}, 0.027 \mathrm{Ni}$ and the remainder is iron.

About the measurements and analysis, percent of $\mathrm{C}, \mathrm{H}$ and $\mathrm{N}$ elements have been analyzed using PerkinElmer $2400 \mathrm{CHN}$ Elemental analyzer. IR spectra have been recorded by Perkin-Elmer 1430 IR spectrophotometer within $4000-400 \mathrm{~cm}^{-1}$ range in the form of $\mathrm{KBr}$ disks. El-MS of the ligand was recorded at $70 \mathrm{eV} .{ }^{1} \mathrm{H}-\mathrm{NMR}$ spectrum has been measured using Varian Mercury Oxford NMR $300 \mathrm{MHz}$ spectrophotomete and using $\mathrm{d}^{6}$-DMSO as the solvent in existence of internal standard, tetramethylsilane. 
523 conductivity bridge has been used for the measurement of molar conductance at $25^{\circ} \mathrm{C}$ using $10^{-3} \mathrm{M}$ solution of each complex dissolved in DMF. TG-50 thermogravimetric instrument has been used for the thermogravimetric analysis of the metal chelates under $10{ }^{\circ} \mathrm{C} / \mathrm{min}$ heating rate and nitrogen atmosphere from room temperature up to $800^{\circ} \mathrm{C}$. The UV-Vis spectra were recorded on a Shimadzu UV-3600 spectrophotometer. The magnetic susceptibilities of the solid metal chelates were measured at $25{ }^{\circ} \mathrm{C}$ using Gouy's method.

PDP and EIS experiments were performed on the PGSTAT30 potentiostat/galvanostat with a temperaturecontrolled system. Prior to each experiment, the working electrode (Sabic iron) was prepared as previous reports [35-37] and was rinsed into the corrosive medium (1.0 M HCl solution) without and with the required quantity at open circuit potential (OCP) which reached after about $30 \mathrm{~min}$. of rinsing in the solution. In PDP, the potential was automatically altered within (-200 to $+200 \mathrm{mV}$ vs. OCP) with a scan rate of $2.0 \mathrm{mV} / \mathrm{s}$. In EIS, the experiments were functioned within frequency range: $100 \mathrm{kHz}$ to $0.1 \mathrm{~Hz}$, and with the amplitude was $4.0 \mathrm{mV}$ (peak to peak) utilizing AC signals at OCP. ML experiments were carried out in a temperature-controlled system. Sabic iron samples were prepared for these experiments also as reported [35-37]. Surface morphology of Sabic iron surfaces was examined before and after addition of a $200 \mathrm{mg} / \mathrm{l}$ of the examined compounds utilizing JEOL Scanning Electron Microscope (SEM) model T-200 with a repeat voltage of $10.0 \mathrm{kV}$.

\subsection{Synthesis of the ligands}

In an HP-500 process vial the mixture of 0.003 mole of $\mathrm{N}$-substituted isatin and 0.003 mole of thiosemicarbazone and $15 \mathrm{~mL}$ of EtOH with $0.5 \mathrm{ml}$ of $\mathrm{HCl}$ were mixed and subjected to microwaves irradiation using pressurized conditions at $110^{\circ} \mathrm{C}$ with $800 \mathrm{~W}$ power for $30 \mathrm{~min}$. The formed yellow $\mathrm{N}$ substituted-istin-thiosemicarbazones 4 (EOIT) and $\mathbf{5}$ (BOIT) were collected by usual way and recrystallized from EtOH.

\subsubsection{1-(1-Ethoxycarbonylmethyl-2-oxoindolin-3-ylidene)thiosemicarbazide 4 (EOIT)}

Yield: $0.89 \mathrm{~g}$ (97\%); m.p. $158{ }^{\circ} \mathrm{C}$; Anal. Calcd (\%) for EOIT $\left(\mathrm{C}_{13} \mathrm{H}_{14} \mathrm{~N}_{4} \mathrm{O}_{3} \mathrm{~S} ; 306.34 \mathrm{~g} \mathrm{~mol}^{-1}\right)$ : C, 50.97; H, 4.41; $\mathrm{N}, 18.29$. Found: $\mathrm{C}, 50.92 ; \mathrm{H}, 4.45 ; \mathrm{N}, 18.25$; IR ( $\mathrm{cm}^{-1}, \mathrm{KBr}$ phase): 3377, $3238(\mathrm{u}(\mathrm{NH})), 1743(\mathrm{u}(\mathrm{C}=\mathrm{O}$ ester)), 1697 (u(C=O indole), $1557(\mathrm{u}(\mathrm{C}=\mathrm{N})), 1288(\mathrm{u}(\mathrm{C}=\mathrm{S})) ;{ }^{1} \mathrm{H}-\mathrm{NMR}\left(850 \mathrm{MHz}, \mathrm{DMSO}-\mathrm{d}^{6}, \mathrm{~d}, \mathrm{ppm}\right): \mathrm{d}: 1.2$ (t, J = $\left.7.65 \mathrm{~Hz}, 3 \mathrm{H}, \mathrm{CH}_{3}\right), 4.15\left(\mathrm{q}, \mathrm{J}=7.65 \mathrm{~Hz}, 2 \mathrm{H}, \mathrm{CH}_{2}\right), 4.67\left(\mathrm{~s}, 2 \mathrm{H}, \mathrm{CH}_{2}\right), 7.15-7.73(\mathrm{~m}, 4 \mathrm{H}, \mathrm{Ar}-\mathrm{H}), 8.78(\mathrm{~s}, 1 \mathrm{H}, \mathrm{NH})$, $9.13(\mathrm{~s}, 1 \mathrm{H}, \mathrm{NH}), 12.23(\mathrm{~s}, 1 \mathrm{H}, \mathrm{NH})$;

\subsubsection{1-(1-Benzyl-2-oxoindolin-3-ylidene)thiosemicarbazide 5 (BOIT)}

Yield: $0.874 \mathrm{~g}$ (94 \%); m.p. 148-150 ${ }^{\circ} \mathrm{C}$ [38]; Anal. Calcd (\%) for BOIT $\left(\mathrm{C}_{16} \mathrm{H}_{14} \mathrm{~N}_{4} \mathrm{OS} ; 310.37 \mathrm{~g} \mathrm{~mol}^{-1}\right)$ : C, 61.92; H, 4.55; N, 18.05. Found: C, 61.97; H, 4.51; N, 17.96; IR ( $\mathrm{cm}^{-1}, \mathrm{KBr}$ phase): 3456, $3257(\mathrm{u}(\mathrm{NH})), 1681$ $(\mathrm{u}(\mathrm{C}=0)), 1588(\mathrm{u}(\mathrm{C}=\mathrm{N})), 1275(\mathrm{u}(\mathrm{C}=\mathrm{S}))$.

\subsection{Synthesis of metal complexes}




\subsubsection{EOIT-Co ([CO(EOIT)Cl] $\left.1.5 \mathrm{H}_{2} \mathrm{O}\right)$}

A hot methanolic solution containing $0.476 \mathrm{~g}$ of $\mathrm{CoCl}_{2} \cdot 6 \mathrm{H}_{2} \mathrm{O}(0.002 \mathrm{~mol})$ in $5 \mathrm{~mL}$ methanol was gradually poured to $30 \mathrm{ml}$ of hot methanol solvent in which $0.612 \mathrm{~g}$ of POIT $(0.001 \mathrm{~mol})$ was dissolved. The resultant mixture was kept refluxed in water path for $4 \mathrm{~h}$ at $65^{\circ} \mathrm{C}$ during which brownish product appeared. Such brown precipitate filtered off from the hot solution, washed with $\mathrm{MeOH}$ and ultimately dried under vacuum. Yield: $59 \%$; m.p. $>300{ }^{\circ} \mathrm{C} ; \Lambda_{\mathrm{m}}\left(\mathrm{W}^{-1} \mathrm{~cm}^{2} \mathrm{~mol}^{-1}\right)=26.6$ Anal. Calcd for EOIT-Co $\left(\mathrm{C}_{13} \mathrm{H}_{16} \mathrm{ClCoN}_{4} \mathrm{O}_{4.5} \mathrm{~S}\right.$; $426.74 \mathrm{~g} \mathrm{~mol}^{-1}$ ) (\%): C, 36.59; H, 3.78; N, 13.13; Co, 13.81. Found: C, 36.66; H, 3.84; N, 13.24; Co, 13.90; ESI$\mathrm{MS} \mathrm{m} / \mathrm{z}=399.5[\mathrm{M}]$ (excluding $1.5 \mathrm{H}_{2} \mathrm{O}$ of hydration), IR ( $\mathrm{cm}^{-1}, \mathrm{KBr}$ phase): $3380,3241(\mathrm{u}(\mathrm{NH})), 1743$ $(\mathrm{u}(\mathrm{C}=0$ ester $)), 1635(\mathrm{u}(\mathrm{C}=0$ indole $)), 1530(\mathrm{u}(\mathrm{C}=\mathrm{N})), 1257(\mathrm{u}(\mathrm{C}-\mathrm{S})), 510(\mathrm{u}(\mathrm{M}-\mathrm{O})), 424(\mathrm{u}(\mathrm{M}-\mathrm{N}))$.

\subsubsection{EOIT-Cu ([Cu(EOIT)Cl])}

Following the same synthetic procedures used for synthesis of EOIT-Co, EOIT-Cu has been synthesized using $0.34 \mathrm{~g}$ of $\mathrm{CuCl}_{2} \cdot 2 \mathrm{H}_{2} \mathrm{O}(0.002 \mathrm{~mol})$ instead of $\mathrm{CoCl}_{2} \cdot 6 \mathrm{H}_{2} \mathrm{O}$. The deep yellowish product obtained is characterized by the following: Colour: deep yellow; Yield: $71 \%$; m.p. $230{ }^{\circ} \mathrm{C} ; \Lambda_{\mathrm{m}}\left(\mathrm{W}^{-1} \mathrm{~cm}^{2} \mathrm{~mol}^{-1}\right)=23.2$; Anal. Calcd for EOIT-Cu $\left(\mathrm{C}_{13} \mathrm{H}_{13} \mathrm{ClCuN}_{4} \mathrm{O}_{3} \mathrm{~S} ; 404.33 \mathrm{~g} \mathrm{~mol}^{-1}\right)$ (\%): C, 38.62; H, 3.24; N, 13.86; Co, 15.72. Found: C, 38.58; H, 3.29; N, 13.93; Co, 16.55; ESI-MS m/z = 401 [M-3]; IR ( $\mathrm{cm}^{-1}, \mathrm{KBr}$ phase): 3394, 3220 $(\mathrm{u}(\mathrm{NH})), 1743(\mathrm{u}(\mathrm{C}=0$ ester $)), 1615(\mathrm{u}(\mathrm{C}=\mathrm{O}$ indole $)), 1541(\mathrm{u}(\mathrm{C}=\mathrm{N})), 1288(\mathrm{u}(\mathrm{C}=\mathrm{S})), 560(\mathrm{u}(\mathrm{M}-\mathrm{O})), 453(\mathrm{u}(\mathrm{M}-$ $\mathrm{N})$ ).

\subsubsection{BOIT-Co ([Co(BOIT) $\left.\left.\mathrm{Cl}_{2}\left(\mathrm{H}_{2} \mathrm{O}\right)\right] \cdot 5 \mathrm{H}_{2} \mathrm{O}\right)$}

As above mentioned in the synthesis of the EOIT complexes, the same synthetic procedures were applied to synthesis BOIT-Co in which $0.476 \mathrm{~g}$ of $\mathrm{CoCl}_{2} \cdot 6 \mathrm{H}_{2} \mathrm{O}(0.002 \mathrm{~mol})$ and $0.621 \mathrm{~g}$ of BOIT $(0.002 \mathrm{~mol})$ each dissolved in hot methanolic solvent were used. The deep brown precipitate separated out is characterized by the following: Colour: deep brown; Yield: $74 \%$; m.p. $>300{ }^{\circ} \mathrm{C} ; \Lambda_{\mathrm{m}}\left(\mathrm{W}^{-1} \mathrm{~cm}^{2} \mathrm{~mol}^{-1}\right)=19.5$; Anal. Calcd for BOIT-Co $\left(\mathrm{C}_{16} \mathrm{H}_{26} \mathrm{Cl}_{2} \mathrm{CoN}_{4} \mathrm{O}_{7} \mathrm{~S} ; 548.3 \mathrm{~g} \mathrm{~mol}^{-1}\right)(\%)$ : C, 35.05; $\mathrm{H}, 4.78 ; \mathrm{N}, 10.22 ; \mathrm{Co}, 10.75$. Found: $\mathrm{C}, 35.12 ; \mathrm{H}$, 4.84; N, 10.27; Co, 10.98; ESI-MS m/z = 496.02 [M + 2] (excluding $3 \mathrm{H}_{2} \mathrm{O}$ of hydration); $\mathrm{IR}\left(\mathrm{cm}^{-1}, \mathrm{KBr}\right.$ phase): 3441, $3241(\mathrm{u}(\mathrm{NH})), 1635(\mathrm{u}(\mathrm{C}=0)), 1558(\mathrm{u}(\mathrm{C}=\mathrm{N})), 1249(\mathrm{u}(\mathrm{C}=\mathrm{S})), 524(\mathrm{u}(\mathrm{M}-\mathrm{O})), 470(\mathrm{u}(\mathrm{M}-\mathrm{N}))$.

\subsection{4. $\mathrm{BOIT}-\mathrm{Cu}([\mathrm{Cu}(\mathrm{BOIT}) \mathrm{Cl}] \cdot \mathrm{Cl})$}

$0.34 \mathrm{~g}$ of $\mathrm{CuCl}_{2} .2 \mathrm{H}_{2} \mathrm{O}(0.002 \mathrm{~mol})$ and $0.621 \mathrm{~g}$ of BOIT $(0.002 \mathrm{~mol})$ dissolved in hot methanol were used and following typical synthetic procedures for the other complexes mentioned above. The deep yellow precipitate obtained is characterized by the following: Colour: deep yellow; Yield: $66 \%$; m.p. $254^{\circ} \mathrm{C}$ (chairing); $\Lambda_{\mathrm{m}}\left(\mathrm{W}^{-1} \mathrm{~cm}^{2} \mathrm{~mol}^{-1}\right)=85$; Anal. Calcd for BOIT-Cu $\left(\mathrm{C}_{16} \mathrm{H}_{14} \mathrm{Cl}_{2} \mathrm{CuN}_{4} \mathrm{OS} ; 444.83 \mathrm{~g} \mathrm{~mol}^{-1}\right)(\%)$ : , 43.20; H, 3.17; N, 12.60; Cu, 14.29. Found: C, 43.15; H, 3.11; N, 12.64; Cu, 14.76; ESI-MS m/z = 444 [M]; IR $\left(\mathrm{cm}^{-1}, \mathrm{KBr}\right.$ phase): 3432, $3238(\mathrm{u}(\mathrm{NH})), 1642(\mathrm{u}(\mathrm{C}=0)), 1574(\mathrm{u}(\mathrm{C}=\mathrm{N})), 1289(\mathrm{u}(\mathrm{C}=\mathrm{S})), 574(\mathrm{u}(\mathrm{M}-\mathrm{O})), 424$ $(\mathrm{u}(\mathrm{M}-\mathrm{N}))$. 


\section{Results And Discussion}

\subsection{Synthetic routes and structures of the two ligands EOIT and BOIT}

The two valuable thiosemicarbazone ligands EOIT and BOIT (compounds 4 \& 5, respectively in Scheme 1) were synthesized as sketched in Scheme 1 from the condensation of $\mathrm{N}$-substituted isatin derivatives 2 and $\mathbf{3}$ with the thiosemicarbazide 1 under the known acidic method in $\mathrm{EtOH} / \mathrm{HCl}$ under reflux for only 10 min under microwaves irradiations as reported previously [39]. The ${ }^{1} \mathrm{H}$ NMR spectrum for the EOIT in dimethylsulfoxide- $d_{6}$ is described in Figure 1. This ${ }^{1} \mathrm{H}$ NMR data glistened with the four singlet signals at $\delta$ $=4.67\left(\underline{\mathrm{CH}}_{2} \mathrm{COOEt}\right), 8.78,9.13,12.23(3 \mathrm{NH}) \mathrm{ppm}$, the appearance of the two protons of the amino group $\left(\mathrm{NH}_{2}\right)$ with two different chemical shift values at $\delta=8.78$ and $9.13 \mathrm{ppm}$ this means that they are magnetically different due to intramolecular-hydrogen bond which restricted or slowed rotation about the $\mathrm{N}-\mathrm{C}$ bond $[40,41]$. In addition, the presence of the two triplet $\left(\mathrm{CH}_{3}\right)$ and the quartet $\left(\mathrm{CH}_{2}\right)$ for the ethyl ester protons at $\delta=1.2$ and $4.15 \mathrm{ppm}$.

\subsection{Comprehensive properties and constitution}

All the physical, spectral and analytical data describing the two used ligands, POIT \& BOIT and their Co(II) \& $\mathrm{Cu}$ (II) chelates, POIT-Co, POIT-Cu, BOIT-Co and BOIT-Cu are illustrated in experimental section. Investigation of these results indicated good correlation between the found and calculated percent of carbon, hydrogen, nitrogen and metal content assuring the proposed composition of the metal chelates and also assuring the formation of the complexes in 1:1 (M:L) ration. The molar conductivity of complexes EOIT-Co, EOIT-Cu, BOIT-Co measured from $10^{-4} \mathrm{M}$ solution of dimethyl formamide were found to lie within $19.5-26.6\left(\mathrm{~W}^{-1} \mathrm{~cm}^{2} \mathrm{~mol}^{-1}\right)$ range which strongly supported the formation of non-conductance neutral complexes [42, 43]. On the other hand, the quite high value of molar conductance of BOIT-Cu; 85 $\mathrm{W}^{-1} \mathrm{~cm}^{2} \mathrm{~mol}^{-1}$, strongly recommended formation of 1:1 (cationic: $\mathrm{Cl}^{-}$) electrolytic complex. The electrolytic or non-electrolytic behaviors of the complexes were qualitatively proved by the precipitation test with aqueous $\mathrm{AgNO}_{3}$ solution where only BOIT-Cu formed the white $\mathrm{AgCl}$ precipitate. Thus the formed complexes has been corroborated to have the formulae [Co(EOIT)Cl] $1.5 \mathrm{H}_{2} \mathrm{O},[\mathrm{Cu}(\mathrm{EOIT}) \mathrm{Cl}],\left[\mathrm{Co}(\mathrm{BOIT}) \mathrm{Cl}_{2}\left(\mathrm{H}_{2} \mathrm{O}\right)\right] \cdot 5 \mathrm{H}_{2} \mathrm{O}$ and [Cu(BOIT)Cl]·Cl for EOIT-Co, EOIT-Cu, BOIT-Co and BOIT-Cu, successively. Solubility test of the metal chelates indicated that all the compounds are readily soluble in most polar solvent while hardly soluble or insoluble in alternative non-polar solvents.

\subsection{Mass spectroscopy}

Information excluded from the mass spectroscopy of the four isolated chelates have been investigated as it provides sufficient evidence to conclude the formula weights of the compounds in addition to their fragments and hence ensures the formation the complexes in the proposed formulae. The mass spectra of complexes EOIT-Co, EOIT-Cu, BOIT-Co and BOIT-Cu are illustrated in Figures 2 and 3. The molecular ion peak appearing in the spectra of complexes EOIT-Co, EOIT-Cu, BOIT-Co and BOIT-Cu at $\mathrm{m} / \mathrm{z}=399.5,401$, 496.02 and 444 amu have been assigned for [M], [M-3], [M+2] and [M], successively, excluding all the 
hydration water for EOIT-Co and 3 of the hydration water for BOIT-Co supporting the proposed formulae of the metal complexes. The multi-peaks and other fragments are formed by cleavage at alternative positions in the complexes molecules..

\subsection{FTIR spectra assignments}

Comparison of the IR spectrum of each of EOIT and BOIT with that of their metal chelates is beneficial method to assign the binding function groups of the ligand to the cobalt or copper centers in the metal complexes and hence can help in structure identification of the metal complexes. From the spectrum of EOIT and BOIT, the bands obvious at 3377, 3238, 1743, 1697, $1557 \& 1288 \mathrm{~cm}^{-1}$ for EOIT and at 3456, $3257,1681,1588 \& 1275 \mathrm{~cm}^{-1}$ for BOIT. These bands, respectively, has been attributed to the stretching vibrations of $\mathrm{NH}($ asy), $\mathrm{NH}(\mathrm{sym}), \mathrm{C}=\mathrm{O}, \mathrm{C}=\mathrm{N}$, and $\mathrm{C}=\mathrm{S}$ [33]. All these bands underwent a position movement in complexes spectra owing to different reasons which helped in structure identification through assignment of binding modes. Firstly, the symmetric and asymmetric stretching vibrations of $\mathrm{NH}$ of amino group appearing in the ranges $3441-3380 \mathrm{~cm}^{-1}$ and $3257-3220 \mathrm{~cm}^{-1}$, undergoing a shift in their position whenever compared with the same bands in the ligand's spectra. Such shift is mostly due to the participation of the group in hydrogen bond with the nearest electronegative atoms which coincided with the generation of alternative medium to weak intensity bands inside the range $2831-2710 \mathrm{~cm}^{-1}$ [43]. On the other hand, the significant shift recorded in the position of $\mathrm{C}=\mathrm{O}, \mathrm{C}=\mathrm{N}$ and $\mathrm{CS}(\mathrm{C}=\mathrm{S}$ or $\mathrm{C}-\mathrm{S})$ peaks in the spectra of complexes upon comparison with their place in the ligand spectra has been explained by the coordination of the ligand to the $\mathrm{Co}$ or $\mathrm{Cu}$ centers as OSN tridentate monobasic thiol (i.e. EOIT-Co) or neutral thione (i.e. EOIT-Cu, BOIT-Co and EOIT-Cu) modes of chelation $[21,44]$. Further support of the coordination of the carbonyl oxygen and azomethine nitrogen to the metal center is the appearance of two bands in the spectra of metal chelates within the ranges $574-510 \mathrm{~cm}^{-1}$ and $470-424 \mathrm{~cm}^{-1}$ with no corresponding bands in the spectra of free ligands. Such bands correspond to the stretching vibrations of $\mathrm{M}-\mathrm{O}$ and $\mathrm{M}-\mathrm{N}$ bonds, respectively [43].

\subsection{Thermogravimetric analysis}

Thermal responses of the metal chelates have been evaluated through TG analysis (thermogravimetric analysis). The TG thermograms of the four compounds are illustrated in Figure 4. From these thermograms it is obvious that the metal complexes decomposed within either two steps (EOIT-Cu), three steps (BOIT-Cu), four steps (EOIT-Co) or within five stages (BOIT-Co). The two steps thermogram of EOIT$\mathrm{Cu}$ showed the first step of degradation within the temperature range $25-238{ }^{\circ} \mathrm{C}$ with weight loss of $33.67 \%$ (calcd $33.78 \%$ ) which assigned to the loss of $1 / 2 \mathrm{Cl}_{2}$ and the organic fragment $\mathrm{C}_{4} \mathrm{H}_{7} \mathrm{NO}_{2}$. The rest of organic moiety completely lost giving $\mathrm{Cu}$ metal as residual product. For BOIT-Cu, the decomposition of the complex that occurred within three stages started at room temperature where the first step extended to $198{ }^{\circ} \mathrm{C}$ corresponding to loss of $8.36 \%$ (calcd $7.96 \%$ ) of the total weight which corresponded to the forfeiture $1 / 2 \mathrm{Cl}_{2}$ of coordinated chloride. The following step which occurred within v198-262 ${ }^{\circ} \mathrm{C}$ range assigned to the loss of $11.93 \%$ (calcd 11.67) of the total weight and within this stage, the counter chloride 
anion get lost in addition to $\mathrm{NH}_{2}$ group. The last and third step appeared in the range $262-566^{\circ} \mathrm{C}$ and appointed to the forfeiture of the rest of organic ligand with mass loss of $62.11 \%$ (calcd $62.57 \%$ ) leaving $\mathrm{CuO}$ as residual product.

Thermal decomposition of the EOIT-Co and BOIT-Co occur according to the following Schemes (see Supplemental Files)

\subsection{Electronic spectra and magnetic moments}

UV-Vis spectra is regarded as one of the most helpful tools to assign the geometrical architectures around the metal centers and also to assure the binding modes of the ligands to the central metal ion. The UV-Vis of the two ligands EOIT \& BOIT and their Co(II) \& Cu(II) chelates, EOIT-Co, EOIT-Cu, BOIT-Co and BOITCu were measured from DMSO solutions. Investigation of the spectra of the ligands indicated that spectral bands apparent at $265 \& 370 \mathrm{~nm}$ and at $264 \& 375 \mathrm{~nm}$ in the spectrum of EOIT \& BOIT, respectively, are assignable to $\pi \rightarrow \pi^{*}$ and $n \rightarrow \pi^{*}$ transitions, respectively $[43,45]$. Such transitions underwent a movement in their place in the spectra of metal chelates (Table 1) assuring the attachment of the azomethine nitrogen to the metal centers.

Addition to the to $\pi \rightarrow \pi^{*}$ and $n \rightarrow \pi^{*}$ transition bands appearing in the spectra of all complexes, the spectrum of the $\mathrm{Co}$ (II) complex EOIT-Co showed the medium to low intensity bands in the visible region at $528 \& 736 \mathrm{~nm}$, for EOIT-Co which are credited to ${ }^{4} \mathrm{~A}_{2} \rightarrow{ }^{4} \mathrm{~T}_{1}\left(\mathrm{U}_{2}\right)$ and ${ }^{4} \mathrm{~A}_{2} \rightarrow{ }^{4} \mathrm{~T}_{1}(\mathrm{P})\left(\mathrm{U}_{3}\right)$ transitions, respectively, assuring four coordinate tetrahedral stereochemistry around $\mathrm{Co}$ (II) ions [46]. For the six coordinated $\mathrm{Co}$ (II) chelate and BOIT-Co, The spectrum exhibited low intensity bands at $588 \mathrm{~nm}$ assigned to ${ }^{4} \mathrm{~T}_{1 \mathrm{~g}}(\mathrm{~F}) \rightarrow{ }^{4} \mathrm{~A}_{2 \mathrm{~g}}(\mathrm{~F})$. The shoulder band appearing at $483 \mathrm{~nm}$ that can be assigned to ${ }^{4} \mathrm{~T}_{1 \mathrm{~g}}(\mathrm{~F}) \rightarrow{ }^{4} \mathrm{~T}_{1 \mathrm{~g}}(\mathrm{p})$. Such transitions are characteristic for octahedral Co(II) chelates [47]. The values of the $\mu_{\text {eff }}$ was measured to be 4.25 and 4.63 B.M. for EOIT-Co and BOIT-Co, successively, which are close to reported values for high spin tetrahedral [48] and octahedral [1] Co(II) complexes.

The spectra of $\mathrm{Cu}$ (II) complexes; EOIT-Cu and BOIT-Cu complexes also allowed broad with low intensity bands at the low energy region which centered at 737 and $676 \mathrm{~cm}^{-1}$, respectively corresponding to ${ }^{2} \mathrm{~B}_{1 \mathrm{~g}} \rightarrow{ }^{2} \mathrm{~A}_{1 \mathrm{~g}}$ transitions special for square planar divalent copper chelates [46]. The two complexes afforded $\mu_{\text {eff }}$ values of 1.82 and 1.88 B.M. for EOIT-Cu and BOIT-Cu, respectively, which supports the results of electronic spectra.

ว 1: Electronic absorption results and $\mu_{\text {eff }}$ values of the $\mathrm{Co}$ (II) and $\mathrm{Cu}$ (II) under interest 


\begin{tabular}{|c|c|c|c|c|}
\hline Complex & $\begin{array}{c}\text { Wavelength } \\
\left(\mathrm{cm}^{-1}\right)\end{array}$ & Assignment & Geometry & $\begin{array}{c}\mu_{\text {eff }} \\
\text { (B.M.) }\end{array}$ \\
\hline EOIT & $\begin{array}{l}265 \\
370\end{array}$ & $\begin{array}{c}\Pi-\Pi^{*} \\
n-\Pi^{*}\end{array}$ & - & - \\
\hline EOIT-Co & $\begin{array}{l}273 \\
374 \\
528 \\
736\end{array}$ & $\begin{array}{c}\Pi-\Pi^{*} \\
\mathrm{n}-\Pi^{*} \\
{ }^{4} \mathrm{~A}_{2} \rightarrow{ }^{4} \mathrm{~T}_{1}\left(\mathrm{v}_{2}\right) \\
{ }^{4} \mathrm{~A}_{2} \rightarrow{ }^{4} \mathrm{~T}_{1}(\mathrm{P})\left(\mathrm{v}_{3}\right)\end{array}$ & tetrahedral & 4.25 \\
\hline EOIT-Cu & $\begin{array}{l}251 \\
375 \\
737\end{array}$ & $\begin{array}{c}\Pi-\Pi^{*} \\
n-\Pi^{*} \\
{ }^{2} B_{1 g} \rightarrow{ }^{2} A_{1 g}\end{array}$ & square planar & 1.82 \\
\hline BOIT & $\begin{array}{l}264 \\
375\end{array}$ & $\begin{array}{l}\Pi-\Pi^{*} \\
n-\Pi^{*}\end{array}$ & - & - \\
\hline BOIT-Co & $\begin{array}{l}269 \\
359 \\
483 \\
588\end{array}$ & $\begin{array}{c}\Pi-\Pi^{*} \\
\mathrm{n}-\Pi^{*} \\
{ }^{4} \mathrm{~T}_{1 \mathrm{~g}}(\mathrm{~F}) \rightarrow{ }^{4} \mathrm{~T}_{1 \mathrm{~g}}(\mathrm{p}) \\
{ }^{4} \mathrm{~T}_{1 \mathrm{~g}}(\mathrm{~F}) \rightarrow{ }^{4} \mathrm{~A}_{2 \mathrm{~g}}(\mathrm{~F})\end{array}$ & octahedral & 4.63 \\
\hline BOIT-Cu & $\begin{array}{l}252 \\
377 \\
676\end{array}$ & $\begin{array}{c}\Pi-\Pi^{*} \\
\mathrm{n}-\Pi^{*} \\
{ }^{2} \mathrm{~B}_{1 \mathrm{~g}} \rightarrow^{2} \mathrm{~A}_{1 \mathrm{~g}}\end{array}$ & square planar & 1.88 \\
\hline
\end{tabular}

\subsection{X-ray diffraction analysis}

We recorded the XRD patterns for the four $\mathrm{N}$-substituted-isatin-thiosemicarbazone complexes EOIT$\mathrm{CoCl}_{2}, \mathrm{BOIT-CoCl} 2, \mathrm{EOIT}-\mathrm{CuCl}_{2}$ and $\mathrm{BOIT-CuCl}$ to investigate their crystal structures and their size. The first look to the for charts of the XRD of the tested complexes indicated that the two complexes $\mathrm{CoCl}_{2}$ are amorphous and on the opposite side the two Cu-complexes reflected the excellent nano-size of the solid samples. From the calculation the size of the investigated tow crystalline Cu-complexes from Figure 5 using FWHM method and Deby-Scherrer and Bragg equations [49]. The size of the particles was found in the nanometer range: for complex EOIT-CuCl${ }_{2}$ its size equal $22.15 \mathrm{~nm}$ and $\mathbf{B O I T - C u C l}_{2}$ its size equal $26.60 \mathrm{~nm}$.

According to all the previous measurements, the structures and geometry of the metal complexes can be formulated as depicted in Scheme 2

\subsection{Assessment of the corrosion rate of Sabic iron and the inhibition efficacy of the interested}

\section{compounds}

\subsubsection{PDP measurements}


PDP measurements of Sabic steel in $1.0 \mathrm{M} \mathrm{HCl}$ solution without and with various concentrations (100-400 ppm) of the tested compounds were performed at $298 \mathrm{~K}$ and the PDP curves of the complex EOIT-Co (as a representative example) are shown in Figure 6. The corrosion parameters, viz. corrosion potential ( $\left.E_{\text {corr }}\right)$, anodic and cathodic Tafel slopes $\left(\beta_{\mathrm{a}}, \beta_{\mathrm{c}}\right)$, corrosion current density $\left(i_{\mathrm{corr}}\right)$, \% IE and $\theta$ of the organic ligands were determined and located in Table 1. From Figure 6 and the determined corrosion parameters listed in Table 1, it can be realized that adding the examined compounds to the corrosive solution (blank, 1.0 M $\mathrm{HCl}$ ) shifted both anodic and cathodic branches of the polarization curves of the corrosive medium to less current densities indicating delay of both anodic and cathodic reactions and thus inhibition of Sabic iron corrosion. The movement of the $E_{\mathrm{corr}}$ value of Sabic iron in the blank solution to positive directions by the addition of the investigated compounds indicates that these compounds perform as mixed-type inhibitors with a major anodic one [50]. The values of $\beta_{\mathrm{a}}$ and $\beta_{\mathrm{c}}$ did not show obvious change in blank solution and when adding the complexes indicating that the adsorbed compounds' molecules did not alter the anodic metal dissolution or cathodic hydrogen evolution. In addition, the value of $i_{\text {corr }}$ of Sabic iron in the blank solution was found to decrease with raising the compounds concentration, which indicates inhibition effects. The acquired results supported that, under similar experimental conditions, the inhibition efficiencies of the investigated inhibitors were set to slightly increase according to the order: EOIT-Cu > BOIT-Cu > EOIT-CO > BOIT-Co.

e 2. Corrosion parameters obtained from the polarization curves in the corrosion of Sabic iron in $\checkmark \mathrm{HCl}$ solution without and with various concentrations of the investigated compounds at $298 \mathrm{~K}$.

\begin{tabular}{|c|c|c|c|c|c|c|c|}
\hline h. & Inhibitor Conc. (mg/l) & $\begin{array}{c}-E_{\text {corr }} \\
(\mathrm{mV}(\mathrm{SCE}))\end{array}$ & $\begin{array}{c}\beta_{\mathrm{a}} \\
(\mathrm{mV} / \text { dec. })\end{array}$ & $\begin{array}{c}-\beta_{\mathrm{c}} \\
(\mathrm{mV} / \text { dec. })\end{array}$ & $\begin{array}{c}i_{\text {corr }} \\
\left(\mu \mathrm{A} / \mathrm{cm}^{2}\right.\end{array}$ & $\%$ IE & $\boldsymbol{\theta}$ \\
\hline & 0 & -469 & 123 & 118 & 365 & -- & -- \\
\hline \multirow{4}{*}{ [-Co } & 100 & 453 & 129 & 117 & 175 & 52 & 0.52 \\
\hline & 200 & 462 & 125 & 121 & 113 & 69 & 0.69 \\
\hline & 300 & 449 & 131 & 123 & 77 & 79 & 0.79 \\
\hline & 400 & 447 & 126 & 119 & 62 & 83 & 0.83 \\
\hline \multirow{4}{*}{ [-Co } & 100 & 465 & 119 & 113 & 186 & 49 & 0.49 \\
\hline & 200 & 460 & 124 & 121 & 124 & 66 & 0.66 \\
\hline & 300 & 463 & 127 & 115 & 91 & 75 & 0.75 \\
\hline & 400 & 449 & 124 & 109 & 69 & 81 & 0.81 \\
\hline \multirow{4}{*}{$-\mathrm{Cu}$} & 100 & 457 & 127 & 116 & 175 & 52 & 0.52 \\
\hline & 200 & 458 & 121 & 111 & 95 & 74 & 0.74 \\
\hline & 300 & 448 & 125 & 114 & 63 & 83 & 0.83 \\
\hline & 400 & 451 & 129 & 118 & 47 & 87 & 0.87 \\
\hline \multirow{4}{*}{$-\mathrm{Cu}$} & 100 & 466 & 132 & 122 & 168 & 54 & $\overline{0.54}$ \\
\hline & 200 & 453 & 127 & 117 & 106 & 71 & 0.71 \\
\hline & 300 & 455 & 118 & 120 & 66 & 82 & 0.82 \\
\hline & 400 & 446 & 123 & 116 & 61 & 83 & 0.83 \\
\hline
\end{tabular}


Corrosion of Sabic iron was studied in $1.0 \mathrm{M} \mathrm{HCl}$ solution in the lack and existence of alternative concentrations of the examined compounds at $298 \mathrm{~K}$ after immersion of the iron samples in the corrosive medium for around $30 \mathrm{~min}$. by EIS technique. The obtained Nyquist and Bode plots of the complex EOIT$\mathrm{Cu}$ (as a representative example) are shown in Figure $7(\mathrm{a}, \mathrm{b})$. It was observed from the Nyquist $(\mathrm{a})$ and Bode plots (b) that the resulted impedance spectra comprised of only depressed capacitive loops in addition to one-time constants, correspondingly, suggesting that adsorption of the tested compounds happens through covering the surface and the corrosion is managed by the process of charge transfer [51]. The acquired communal profile of the plots was similar in both lake and existence of the compounds at the alternative concentrations employed revealing that there was no alter in Sabic iron corrosion mechanism [52]. It was realized from the Nyquist plots that the size of the capacitive semicircle increased by addition of the examined compounds revealing a reduce in the corrosion rate and an increase in the \% Es and the later were increased as the concentrations of the examined compounds increased [53]. Additionally, the Bode phase plots, Figure 7(b), showed that the phase angle was increased with increasing the compounds' concentrations. This indicated that the metal surface was considerably changed to smooth because of formation of a protecting layer of inhibitors' molecules on the Sabic iron surface resulting in a decrease in the corrosion rate [54].

Analysis of the impedance spectra were done through illustrating the model of the equivalent circuit shown in Figure 8. Impedance parameters values such as solution resistance $\left(R_{\mathrm{s}}\right)$, charge transfer resistance $\left(R_{\mathrm{ct}}\right)$, constant phase element (CPE), \% IE and $\theta$ were evaluated from the impedance spectra and were tabulated in Table 3. From these results it is obvious that the addition of the examined compounds to the blank solution leads to increasing the value of $R_{\mathrm{ct}}$ of the corrosive medium and this behavior was set to significantly increased with increasing inhibitors' concentrations. This was associated with a reduce in CPE value as a result of a reduce in the dielectric constant and/or an increase in the double-layer thickness. This indicated adsorption of the investigatd compounds' molecules on the iron/solution interface [55] resulting in the safeguard of the Sabic iron surface from the attack of the corrosive medium. With increasing the concentration of the examined complexes, the inhibition efficiencies were set to increase confirming that these compounds are regarded as efficient inhibitors for the corrosion of Sabic iron in $1.0 \mathrm{M} \mathrm{HCl}$ solution. Variation of inhibition efficiencies with the concentrations of the investigated compounds was illustrated in Figure 9.

3. Values of the impedance parameters of the corrosion of Sabic steel in $1.0 \mathrm{M} \mathrm{HCl}$ solution ut and with various concentrations of the investigated synthesized complexes at $298 \mathrm{~K}$. 


\begin{tabular}{|c|c|c|c|c|c|c|}
\hline libitor & Inhibitor Conc. $(\mathrm{mg} / \mathrm{l})$ & $\begin{array}{l}R_{\mathrm{s}} \\
\left.(\mathrm{ohm} \mathrm{cm})^{2}\right)\end{array}$ & 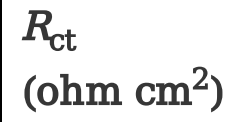 & $\begin{array}{l}\mathrm{CPE} \\
\left(\mu \mathrm{F} / \mathrm{cm}^{2}\right)\end{array}$ & $\%$ IE & $\theta$ \\
\hline & 0 & 1.23 & 71 & 224 & -- & -- \\
\hline \multirow{4}{*}{ IT-Co } & 100 & 2.24 & 127 & 122 & 44 & 0.44 \\
\hline & 200 & 3.07 & 207 & 77 & 66 & 0.66 \\
\hline & 300 & 2.18 & 321 & 62 & 78 & 0.78 \\
\hline & 400 & 3.74 & 423 & 59 & 83 & 0.83 \\
\hline \multirow{4}{*}{ ITT-Co } & 100 & 2.31 & 119 & 133 & 40 & 0.40 \\
\hline & 200 & 1.91 & 187 & 95 & 62 & 0.62 \\
\hline & 300 & 2.07 & 298 & 76 & 76 & 0.76 \\
\hline & 400 & 1.82 & 384 & 59 & 82 & 0.82 \\
\hline \multirow{4}{*}{ IT-Cu } & 100 & 1.05 & 131 & 122 & 46 & 0.46 \\
\hline & 200 & 0.96 & 244 & 73 & 71 & 0.71 \\
\hline & 300 & 3.20 & 368 & 54 & 81 & 0.81 \\
\hline & 400 & 2.33 & 497 & 46 & 85 & 0.85 \\
\hline \multirow{4}{*}{ IT-Cu } & 100 & 0.95 & 142 & 112 & 50 & 0.50 \\
\hline & 200 & 3.40 & 211 & 84 & 66 & 0.66 \\
\hline & 300 & 2.51 & 316 & 63 & 78 & 0.78 \\
\hline & 400 & 1.71 & 458 & 48 & 84 & 0.84 \\
\hline
\end{tabular}

\subsection{3. $M L$ measurements}

Mass loss $(\mathrm{ML})$ recording of Sabic iron in $1.0 \mathrm{M} \mathrm{HCl}$ solution were carried out at specified time intervals in the absence and presence of certain concentrations of the tested compounds at $298 \mathrm{~K}$. Figure 10 shows only the mass-loss versus immersion time plots of the complex BOIT-Co. The same plots were acquired for other investigated compounds but not shown here. Values of the corrosion rates (CR), $\theta$ and \% IE of the examined compounds are also inserted in Table 4. The data listed in Table 4 indicated that the values of CR were decreased while the inhibition efficiencies were enhanced with raising the inhibitors' concentrations which attributed to augmenting adsorption coverage of the inhibitor molecules on the steel surface with rising concentration leading to decrease of the corrosion rates of Sabic iron. Therefore, the examined compounds are regarded as effective inhibitors for Sabic iron corrosion in $1.0 \mathrm{M} \mathrm{HCl}$ solution. In consistence with both PDP and EIS techniques, at similar inhibitors concentration, the \% IEs are slightly increased in the order: EOIT-Cu > BOIT-Cu > EOIT-Co > BOIT-Co. A comparison of the change of the \% IEs of the examined compounds with their concentrations at $298 \mathrm{~K}$, obtained from all used techniques, PDP, EIS and $M L$, is shown in Figure 11 indicating that the results concluded from all employed techniques are in a good consistent with each other's.

э 4. Values of CR (mpy) of Sabic iron, \% IE and $\theta$ of various concentrations of the investigated ıunds in $1.0 \mathrm{M} \mathrm{HCl}$ solution at $298 \mathrm{~K}$. 


\begin{tabular}{|l|l|l|l|l|}
\hline Inhibitor & $\begin{array}{c}\text { Inhibitor } \\
\text { Conc. (mg/l) }\end{array}$ & CR & $\%$ IE & $\theta$ \\
\hline & 0 & 166 & -- & -- \\
\hline \multirow{5}{*}{ EOIT-Co } & 100 & 80 & 52 & 0.52 \\
\cline { 2 - 5 } & 200 & 48 & 71 & 0.71 \\
\cline { 2 - 5 } & 300 & 33 & 80 & 0.80 \\
\cline { 2 - 5 } & 400 & 28 & 83 & 0.83 \\
\hline \multirow{5}{*}{ BOIT-Co } & 100 & 81 & 52 & 0.52 \\
\cline { 2 - 5 } & $\mathbf{2 0 0}$ & 53 & 68 & 0.68 \\
\cline { 2 - 5 } & $\mathbf{3 0 0}$ & 40 & 76 & 0.76 \\
\hline \multirow{5}{*}{ EOIT-Cu } & 400 & 35 & 79 & 0.79 \\
\cline { 2 - 5 } & $\mathbf{1 0 0}$ & 75 & 55 & 0.55 \\
\cline { 2 - 5 } & $\mathbf{3 0 0}$ & 46 & 72 & 0.72 \\
\cline { 2 - 5 } & 400 & 29 & 83 & 0.83 \\
\hline \multirow{5}{*}{ BOIT-Cu } & 100 & 25 & 85 & 0.85 \\
\cline { 2 - 5 } & $\mathbf{2 0 0}$ & 51 & 55 & 0.55 \\
\cline { 2 - 5 } & $\mathbf{3 0 0}$ & 30 & 83 & 0.83 \\
\cline { 2 - 5 } & 400 & 23 & 86 & 0.86 \\
\hline
\end{tabular}

\subsubsection{Adsorption isotherms}

The obtained inhibition efficiencies of the tested compounds were interpreted based on their adsorption on the metal surface. Some adsorption isotherms such as Langmuir, Frumkin, Freundlich, Temkin, etc. have been widely studied to investigate the kind of adsorption of the tested inhibitor molecules on the metallic surfaces and hence the mechanism of corrosion inhibition. In our investigation, Langmuir adsorption isotherm, the relation between the fractional surface coverage ([Inh.]/ $\theta)$ of the examined compounds versus their concentrations [Inh.], according to the following equation [56],

$$
\frac{[\operatorname{Inh} .]}{\theta}=\frac{1}{K_{\text {ads }}}+[\operatorname{Inh} .]
$$

where $K_{\mathrm{ads}}$ is the absorptive equilibrium constant, was fitted and is illustrated in Figure 12. This indicates that the inhibitors adsorption on the surface of Sabic iron was correlated to the Langmuir adsorption isotherm.

\subsubsection{Surface morphology}


SEM images of Sabic iron specimens in a free $1.0 \mathrm{M} \mathrm{HCl}$ (corrosive medium) and with addition of 200 $\mathrm{mg} / \mathrm{l}$ of the investigated compounds are shown in Figure 13(a-f). Figure $13(\mathrm{a})$ and (b) show a polished Sabic iron surface before and after 24 hours immersion in the corrosive medium, successively. Figure 13(b) shows a strong destruction of the surface of iron specimen due to its exposure to the corrosive medium. Figure 13(c) to (f) shows SEM images after addition of a $200 \mathrm{mg} / \mathrm{l}$ of the investigated compounds: EOIT-Co, BOIT-Co, EOIT-Cu and BOIT-Cu, correspondingly, to the corrosive medium. It can be detect that, the surface of Sabic iron specimens were considerably covered with the investigated compounds on the most surface areas which was attributed to strong adsorption of the compounds' molecules on the iron surface, leading to protecting the iron surfaces from the medium, and hence display an efficient corrosion inhibition.

\section{Conclusions}

$\mathrm{Co}$ (II) and $\mathrm{Cu}$ (II) complexes of the two ligands named 1-(1- Ethoxycarbonylmethyl-2-oxoindolin-3-ylidene) thiosemicarbazide (EOIT) and 1-(1-Benzyl-2-oxoindolin-3-ylidene) thiosemicarbazide (BOIT) have been effectively isolated as concluded from the obtained spectral and analytical results. Relaying on such results the composition of the four complexes are assured to [Co(POIT) $\mathrm{Cl}] \cdot 1.5 \mathrm{H}_{2} \mathrm{O},[\mathrm{Cu}(\mathrm{POIT}) \mathrm{Cl}]$, [Co(BOIT) $\left.\mathrm{Cl}_{2}\left(\mathrm{H}_{2} \mathrm{O}\right)\right] \cdot 5 \mathrm{H}_{2} \mathrm{O}$ and [ $\left.\mathrm{Cu}(\mathrm{BOIT}) \mathrm{Cl}\right] \cdot \mathrm{Cl}$ in which the $\mathrm{Cu}(\mathrm{II})$ complexes showed square planar geometry whereas the $\mathrm{Co}$ (II) complexes are either tetrahedral or octahedral. The IR and mass spectra assured the coordination of the ligands to the Co or Cu centers as OSN tridentate monobasic thiol (i.e.

EOIT-Co) or neutral thione (i.e. EOIT-Cu, BOIT-Co and EOIT-Cu) modes of bonds. The compounds were also investigated as inhibitors for the corrosion of Sabic iron in $1.0 \mathrm{M} \mathrm{HCl}$ utilizing various techniques at $298 \mathrm{~K}$. The compounds were set to have high inhibition efficiencies, which were interpreted by strong adsorption of the compounds' molecules on the iron surface and such adsorption was set to follow Langmuir adsorption isotherm. The inhibition efficiencies of these compounds were set to depend on their concentrations and structures. At the same concentration, the inhibition efficiencies are slightly increased in the order: EOIT-Cu > BOIT-Cu > EOIT-Co > BOIT-Co. Finally, the investigational results obtained from all employed techniques were found to be in a good consistent with each other.

\section{Declarations}

\section{Declaration of Interest}

The authors declare that they have no known competing financial interests or personal relationships that could have appeared to influence the work reported in this paper.

\section{References}


1. A. Fawzy, H.A. El-Ghamry, T.A. Farghaly, T.M. Bawazeer, Investigation of the inhibition efficiencies of novel synthesized cobalt complexes of 1,3,4-thiadiazolethiosemicarbazone derivatives for the acidic corrosion of carbon steel, J. Mol. Str. 1203 (2019) 127447.

2. T.M. Bawazeer, H.A. El-Ghamry, T.A. Farghaly, A. Fawzy, Novel 1,3,4-thiadiazolethiosemicarbazones derivatives and their divalent cobalt complexes: Synthesis, characterization and their efficiencies for acidic corrosion inhibition of carbon steel, J. Inorg. Organomet. Polym. Mater. 30 (2020) 1609-1620.

3. M. Alfakeer, M. Abdallah, A. Fawzy, Corrosion inhibition effect of expired ampicillin and flucloxacillin drugs for mild steel in aqueous acidic medium, Int. J. Electrochem. Sci. 15 (2020) 3283 - 3297.

4. M. Abdallah, B. A. Al Jahdaly, M. M. Salem, A. Fawzy, A. A. Abdel Fattah, Pitting corrosion of nickel alloys and stainless steel in chloride solutions and its inhibition using some inorganic compounds, $\mathrm{J}$. Mater. Env. Sci. 8 (2017) 2599-2607.

5. M. Abdallah, M. M. Salem, I. A. Zaafarany, A. Fawzy, A. A. Abdel Fattah, Corrosion performance of stainless steel and nickel alloys in aqueous sodium hydroxide as revealed from cyclic voltammetry and potentiodynamic anodic polarization, Orient. J. Chem. 33 (2017) 2875-2883.

6. M. Abdallah, A. Fawzy, A. Al Bahir, The effect of expired acyclovir and omeprazole drugs on the inhibition of Sabic iron corrosion in HCl solution, Int. J. Electrochem. Sci. 15 (2020) 4739-4753.

7. M. Abdallah, A. Fawzy, H. Hawsawi, Maltodextrin and chitosan polymers as inhibitors for the corrosion of carbon steel in $1.0 \mathrm{M}$ hydrochloric acid, Int. J. Electrochem. Sci. 15 (2020) 5650-5663.

8. M. Abdallah, A. S. Fouda, I. Zaafarany, A. Fawzy, Y. Abdallah, Corrosion inhibition of iron in sulphuric acid solution by antibacterial cephalosporin, J. Am. Sci. 9 (2013) 209-215.

9. M. Amin, M.A. Ahmed, H.A. Arida, F. Kandemirili, M. Saracoglu, T. Arsland, M.A. Basaram, Monitoring corrosion and corrosion control of iron in $\mathrm{HCl}$ by non-ionic surfactants of the TRITON-X series-Part III. Immersion time effects and theoretical studies, Corros. Sci. 53 (2011) 1895-1909.

10. P.B. Raja, M. Ismail, S. Ghoreishiamiri, J. Mirza, M.C. Ismail, S. Kakooei, A.A. Rahim, Reviews on corrosion inhibitors: a short view, Chem. Eng. Commun. 203 (2016) 1145-1156.

11. M.A. Quraishi, J. Rawat, Corros. Rev., 2001, 19, 273.

12. P.B. Raja, M.G. Sethuraman, Natural products as corrosion inhibitor for metals in corrosive media - A review, Mater. Lett. 62 (2008)113-116.

13. N.A. Negm, Y.M. Elkholy, S.M. Tawfik, Corrosion inhibition of carbon steel by some quaternary surface active isoxazol-2-ium cationic Schiff bases in hydrochloric acid solution, Corros. Sci. 53 (2011) 3566-3575.

14. M. Fin`sgar, I. Milo`sev, Inhibition of copper corrosion by 1,2,3-benzotriazole: A review, Corros. Sci. 52 (2010) 2737-2749.

15. N. Lin, S. Stepanow, F. Vidal, K. Kern, M. S. Alam, S. Stromsdorfer, V. Dremov, P. Muller, A. Landa, M. Ruben, Surface-assisted coordination chemistry and self-assembly, Dalton Trans. (2006) 27942800.

16. S. Hettiarachchi, Y.W. Chan, R.B. Wilson, V.S. Agarwala, Phthalocyanine and Polyphthalocyanine Coatings for Corrosion Protection of Metals, MRS Online Proceedings Library, 125(1988) 321-327. 
17. A. Singh, Y. Lin, M. Quraishi, L. Olasunkanmi, O. Fayemi, Y. Sasikumar, B. Ramaganthan, I. Bahadur, I. Obot, A. Adekunle, M. Kabanda, E. Ebenso, Porphyrins as Corrosion Inhibitors for N80 Steel in 3.5\% $\mathrm{NaCl}$ Solution: Electrochemical, Quantum Chemical, QSAR and Monte Carlo Simulations Studies, Molecules 20 (2015) 15122-15146.

18. M. Dibetsoe, L. Olasunkanmi, O. Fayemi, S. Yesudass, B. Ramaganthan, I. Bahadur, A. Adekunle, M. Kabanda, E. Ebenso, Some Phthalocyanine and Naphthalocyanine Derivatives as Corrosion Inhibitors for Aluminium in Acidic Medium: Experimental, Quantum Chemical Calculations, QSAR Studies and Synergistic Effect of lodide lons, Molecules 20 (2015) 15701-15734.

19. T. Peme, L.O. Olasunkanmi, I. Bahadur, A.S. Adekunle, M.M. Kabanda, E.E. Ebenso, Adsorption and Corrosion Inhibition Studies of Some Selected Dyes as Corrosion Inhibitors for Mild Steel in Acidic Medium: Gravimetric, Electrochemical, Quantum Chemical Studies and Synergistic Effect with lodide Ions, Molecules 20 (2015) 16004-16029.

20. G.A. Gazieva, A.N. Kravchenko, Thiosemicarbazides in the synthesis of five and six-membered heterocyclic compounds, Russ. Chem. Rev. 81 (2012) 494-523.

21. J. Haribabu, O.I. Alajrawy, K. Jeyalakshmi, C. Balachandran, D.A. Krishnan, N. Bhuvanesh, S. Aoki, K. Natarajan, R. Karvembu, N-substitution in isatin thiosemicarbazones decides nuclearity of $\mathrm{Cu}$ (II) complexes - Spectroscopic, molecular docking and cytotoxic studies, Spectrochim. Acta A 246 (2021) 118963.

22. C. Balachandrana, J. Haribabub, K. Jeyalakshmib, N.S.P. Bhuvaneshc, R. Karvembub, N. Emia, S. Awaled, Nickel(II) bis(isatin thiosemicarbazone) complexes induced apoptosis through mitochondrial signaling pathway and G0/G1 cell cycle arrest in IM-9 cells, J. Inorg. Biochem. 182 (2018) 208-221.

23. J. Haribabua, G.R. Subhashree, S. Saranya, K. Gomathi, R. Karvembu, D. Gayathri, Isatin based thiosemicarbazone derivatives as potential bioactive agents: Anti-oxidant and molecular docking studies, J. Mol. Struct. 1110 (2016) 185-195.

24. Q. Yuan, R. Cheng, S. Zou, C. Ding, H. Liu, Y. Wang, D. Yang, X. Xiao, Q. Jiang, R. Tang, J. Chen, Isatin thiosemicarbazone derivatives as inhibitors against corrosion of AA6060 aluminium alloy in acidic chloride medium: substituent effects, J. Mater. Res. Technol. 9, 2020, 11935-11947.

25. M. Muralisankar, R. Sreedharan, S. Sujith, N.S.P. Bhuvanesh, A. Sreekanth, N(1)-pentyl isatin-N(4)methyl-N(4)-phenyl thiosemicarbazone (PITSc) as a corrosion inhibitor on mild steel in $\mathrm{HCl}, \mathrm{J}$. Alloys Comp. 695 (2017) 171-182.

26. K.R. Ansari, M.A. Quraishi, A. Singh, Isatin derivatives as a non-toxic corrosion inhibitor for mild steel in 20\% $\mathrm{H}_{2} \mathrm{SO}_{4}$, Corrosion Sci. 95 (2015) 62-70.

27. A.B. da Silva, J.A.C.P. Gomes, E. D’Elia, M.J.C. Rezende, A.C. Pint, B.N.M. Silva, B.V. Silva, IsatinDerived Compounds as Carbon Steel Corrosion Inhibitors in Highly Saline Media, Int. J. Electrochem. Sci. 8 (2013) 9317-9331.

28. D.D.N. Singh, M.M. Singh, R.S. Chaudhary, C.V. Agarwal, Inhibitive effects of isatin, thiosemicarbazide and isatin-3-(3-thiosemicarbazone) on the corrosion of aluminum alloys in nitric acid, J. Appl. Electrochem. 10, 587-592(1980). 
29. T.S. Lobana, R. Sharma, G. Bawa, S. Khanna, Bonding and structure trends of thiosemicarbazone derivatives of metals-an overview, Coord. Chem. Rev. 253 (2009) 977-1055.

30. J. Haribabu, M.M. Tamizh, C. Balachandran, Y. Arun, N.S.P. Bhuvanesh, A. Endo, R. Karvembu, Synthesis, structures and mechanistic pathways of anticancer activity of palladium(II) complexes with indole-3-carbaldehyde thiosemicarbazones, New J. Chem. 42 (2018) 10818-10832.

31. D.X. West, A.E. Liberta, S.B. Padhye, R.C. Chikate, P.B. Sonawane, A.S. Kumbhar, R.G. Yerande, Thiosemicarbazone complexes of copper(II): structural and biological studies, Coord. Chem. Rev. 123 (1993) 49-71.

32. H. Beraldo, D. Gambino, The wide pharmacological versatility of semicarbazones, thiosemicarbazones and their metal complexes, Mini-Rev. Med. Chem. 4 (2004) 31-39.

33. O.A. El-Gammal, A.S. Fouda, D.M. Nabih Novel $\mathrm{Mn}^{2+}, \mathrm{Fe}^{3+}, \mathrm{Co}^{2}, \mathrm{Ni}^{2+}$ and $\mathrm{Cu}^{2+}$ complexes of potential OS donor thiosemicarbazide: Design, structural elucidation, anticorrosion potential study and antibacterial activity, J. Mol. Struct. 1204 (2020) 127495.

34. N.N. Hazani, Y. Mohd, S.A.I.S.M. Ghazali, Y. Farina, N.N. Dzulkifli, Electrochemical studies on corrosion inhibition behaviour of synthesised 2-acetylpyridine 4-ethyl-3-thiosemicarbazone and its tin(IV) complex for mild steel in $1 \mathrm{M} \mathrm{HCl}$ solution, J. Electrochem. Sci. Technol. 10 (2019) 29-36.

35. A. Fawzy, M. Abdallah, I.A. Zaafarany, S.A. Ahmed, I.I. Althagafi, Thermodynamic, kinetic and mechanistic approach to the corrosion inhibition of carbon steel by new synthesized amino acidsbased surfactants as green inhibitors in neutral and alkaline aqueous media, J. Mol. Liq. 265 (2018) 276-291.

36. A. Fawzy, I.A. Zaafarany, H.M. Ali, M. Abdallah, New synthesized amino acids-based Surfactants as efficient inhibitors for corrosion of mild steel in hydrochloric acid medium: Kinetics and thermodynamic approach, Int. J. Electrochem. Sci. 13 (2018) 4575-4600.

37. A. Fawzy, M. Abdallah, M. Alfakeer, H.M. Ali, Corrosion inhibition of Sabic iron in different media using synthesized sodium N-dodecyl arginine surfactant, Int. J. Electrochem. Sci. 14 (2019) 20632084.

38. J. Haribabu, G.R. Subhashree, S. Saranya, K. Gomathi, R. Karvembu, D. Gayathri, Isatin based thiosemicarbazone derivatives as potential bioactive agents: Anti-oxidant and molecular docking studies, J. Mol. Str. 1110 (2016) 185-195.

39. M.M. Amin, M.R. Shaaban, N.T. Al-Qurashi, H.K. Mahmoud, T.A. Farghaly. Indomethacin analogs: synthesis, anti-inflammatory and analgesic activities of indoline derivatives. Mini-Rev. Med. Chem. 18 (2018) 1409-1421.

40. M.M. Alsharekh, I.I. Althagafi, M.R. Shaaban, T.A. Farghaly, Microwave-assisted and thermal synthesis of nanosized thiazolyl-phenothiazine derivatives and their biological activities, Res. Chem. Intermed. 45 (2019) 127-154.

41. I.I. Althagafi, A.S. Abouzied, T.A. Farghaly, N.T. Al-Qurashi, M.Y. Alfaifi, M.R. Shaaban, M.R. Abdel Aziz, Novel Nano-sized bis-indoline Derivatives as Antitumor Agents, J. Heterocycl. Chem. 56 (2019) 391399. 
42. W. Geary, The Use of Conductivity Measurements in Organic Solvents for the Characterisation of Coordination Compounds, Coord. Chem. Rev. 7 (1971) 81-122.

43. N.H. Yarkandi, H.A. El-Ghamry, M. Gaber, Synthesis, spectroscopic and DNA binding ability of Co", Ni", $\mathrm{Cu}^{\prime \prime}$ and $\mathrm{Zn}$ " complexes of Schiff base ligand (E)-1-(( $1 \mathrm{H}$ benzo[d]imidazol-2-

yl)methylimino)methyl)naphthalen-2-ol. X-ray crystal structure determination of cobalt (II) complex, Mater. Sci. Eng. C 75 (2017)1059-1067.

44. K.M. Takroni, T.A. Farghaly, M.F. Harras, H.A. El-Ghamry, Synthesis, structure elucidation, DNA binding and molecular docking studies of novel copper (II) complexes of two 1,3,4thiadiazolethiosemicarbazone derivatives, Appl. Organomet. Chem. 34 (2020) e5860.

45. F. Chioma, A.C. Ekennia, C.U. Ibeji, S.N. Okafor, D.C. Onwudiwe, A.A. Osowole, O.T. Ujam, Synthesis, characterization, antimicrobial activity and DFT studies of 2-(pyrimidin-2-ylamino)naphthalene-1,4dione and its Mn(II), Co(II), Ni(II) and Zn(II) complexes, J. Mol. Struct. 1163 (2018) 455-464.

46. F.A. Saad, H.A. El-Ghamry, M.A. Kassem, A.M. Khedr, Nano-synthesis, biological efficiency and DNA binding affinity of new homo-binuclear metal complexes with sulfa azo dye based ligand for further pharmaceutical applications. J. Inorg. Organomet. Polym. Mater. 29 (2019) 1337-1348.

47. S.A. Sadeek, A.A. Mohamed, H.A. El-Sayed, M.S. El-Attar, Appl. Organomet. Chem. 34 (2020) e5334.

48. M.M. Al-Ne'aimi, M.M. Al-Khuder, Synthesis, characterization and extraction studies of some metal (II) complexes containing (hydrazoneoxime and bis-acylhydrazone) moieties, Spectrochim. Acta A 105 (2013) 365-373.

49. H.K. Mahmoud, B.H. Asghar, M.F. Harras, T.A. Farghaly, Nano-sized formazan analogues: Synthesis, structure elucidation, antimicrobial activity and docking study for COVID-19, Bioorg. Chem. 105 (2020) 104354.

50. G.N. Mu, X.H. Li and Q. Qu, J. Zhou, Molybdate and tungstate as corrosion inhibitors for cold rolling steel in hydrochloric acid solution, Corros Sci 48 (2006) 445-459.

51. J.C. Bessone, K. Mayer, W. Tuttner, J. Lorenz, AC-impedance measurements on aluminium barrier type oxide films, Electrochim. Acta 28 (1983) 171-175.

52. F.M. Reis, H.G. De Melo, I. Costa, EIS investigation on Al 5052 alloy surface preparation for selfassembling monolayer, Electrochim. Acta 51 (2006) 1780-1788.

53. C. Hsu, F. Mansfeld, Technical note concerning the conversion of the constant phase element parameter Y0 into a capacitance, Corrosion 57 (2001) 747.

54. A.M. Muhsen, A. El-Haddad, B. Radwan, M.H. Sliem, W.M.I. Hassan, A. M. Abdullah, Highly efficient eco-friendly corrosion inhibitor for mild steel in $5 \mathrm{M} \mathrm{HCl}$ at elevated temperatures: experimental \& molecular dynamics study, Sci. Reports 9 (2019) 3695.

55. S.Y. Sayed, M.S. El-Deab, B.E. El-Anadouli, B.G. Ateya, Synergistic Effects of Benzotriazole and Copper lons on the Electrochemical Impedance Spectroscopy and Corrosion Behavior of Iron in Sulfuric Acid. J. Phys. Chem. B 107 (2003) 5575.

56. M. Christov, A. Popova, Adsorption characteristics of corrosion inhibitors from corrosion rate measurements. Corros. Sci. 46, 1613-1620 (2004). 
Figures

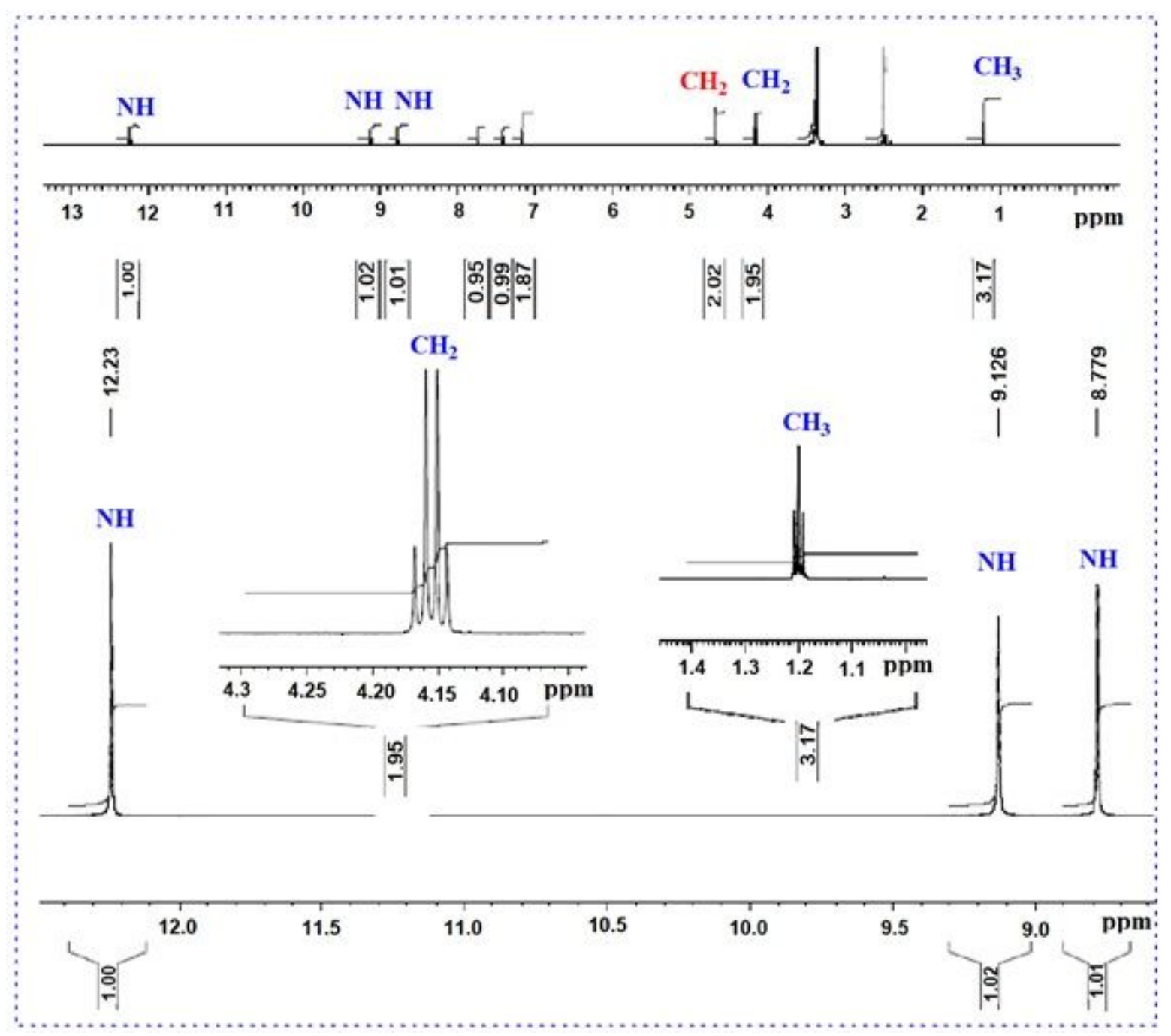

Figure 1

The $1 \mathrm{H}$ NMR of the thiosemicarbazone derivative 4 (EOIT) 


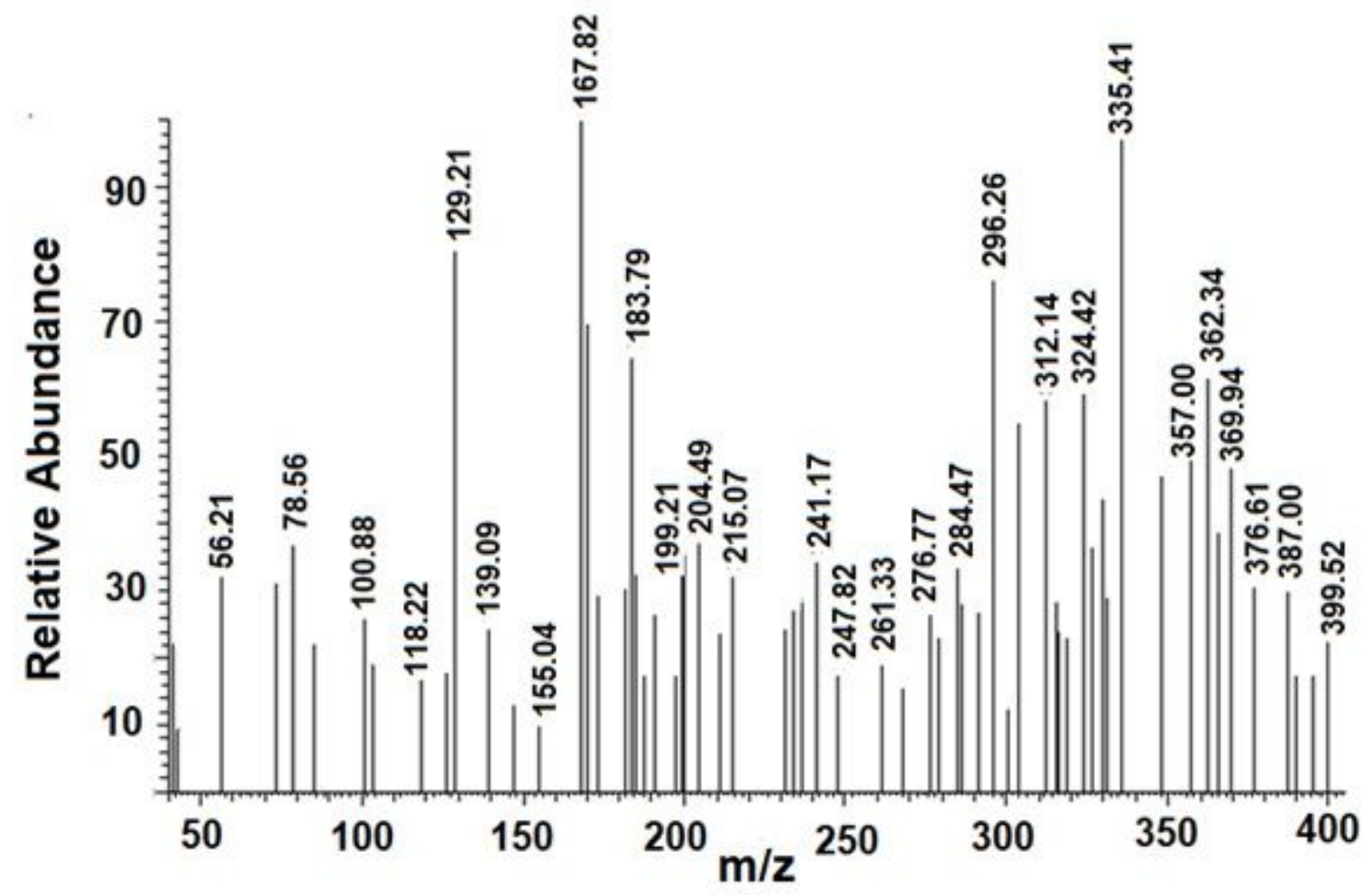

Figure 2

El- mass spectrum of EOIT-Co

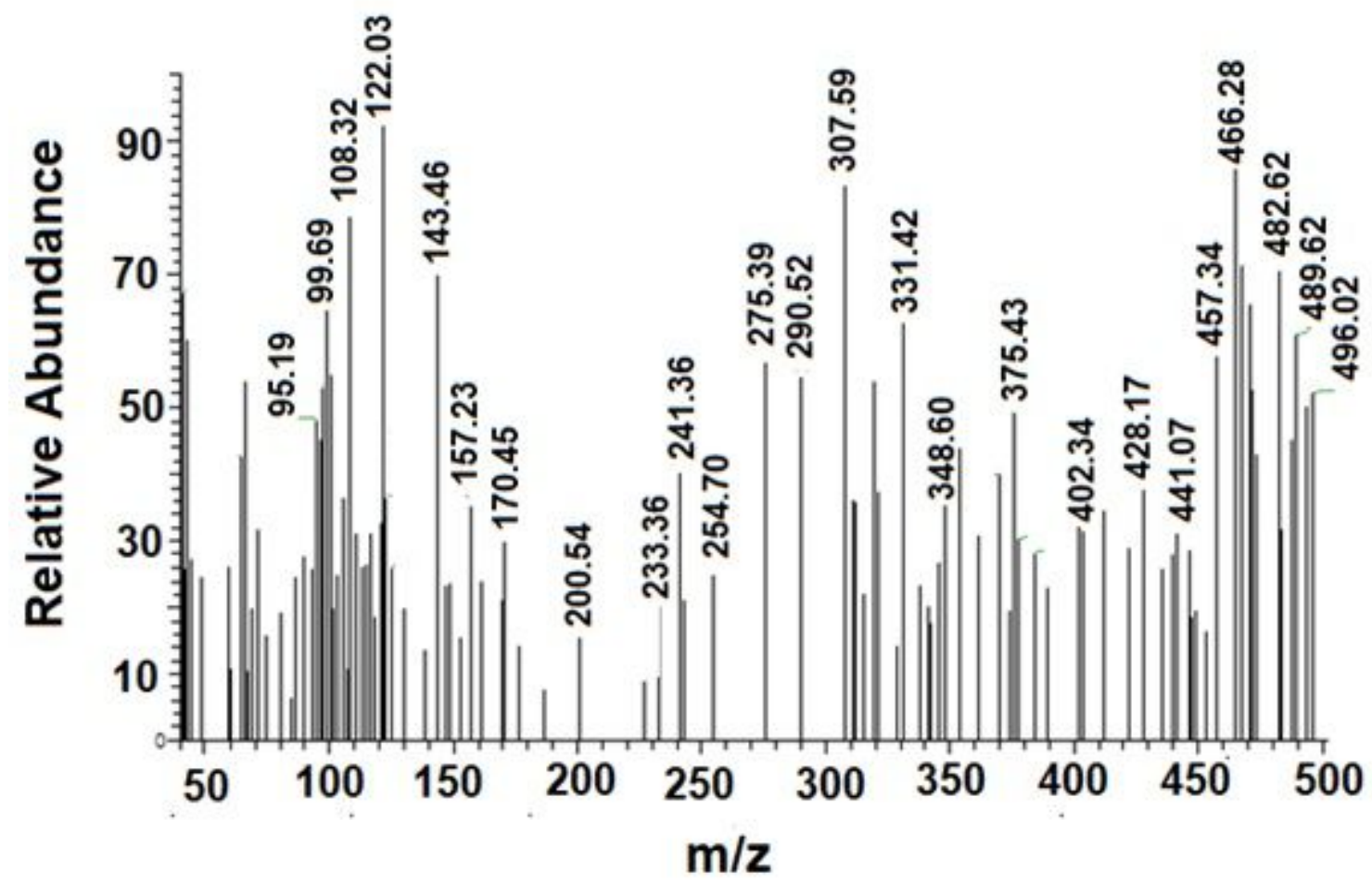

Figure 3 

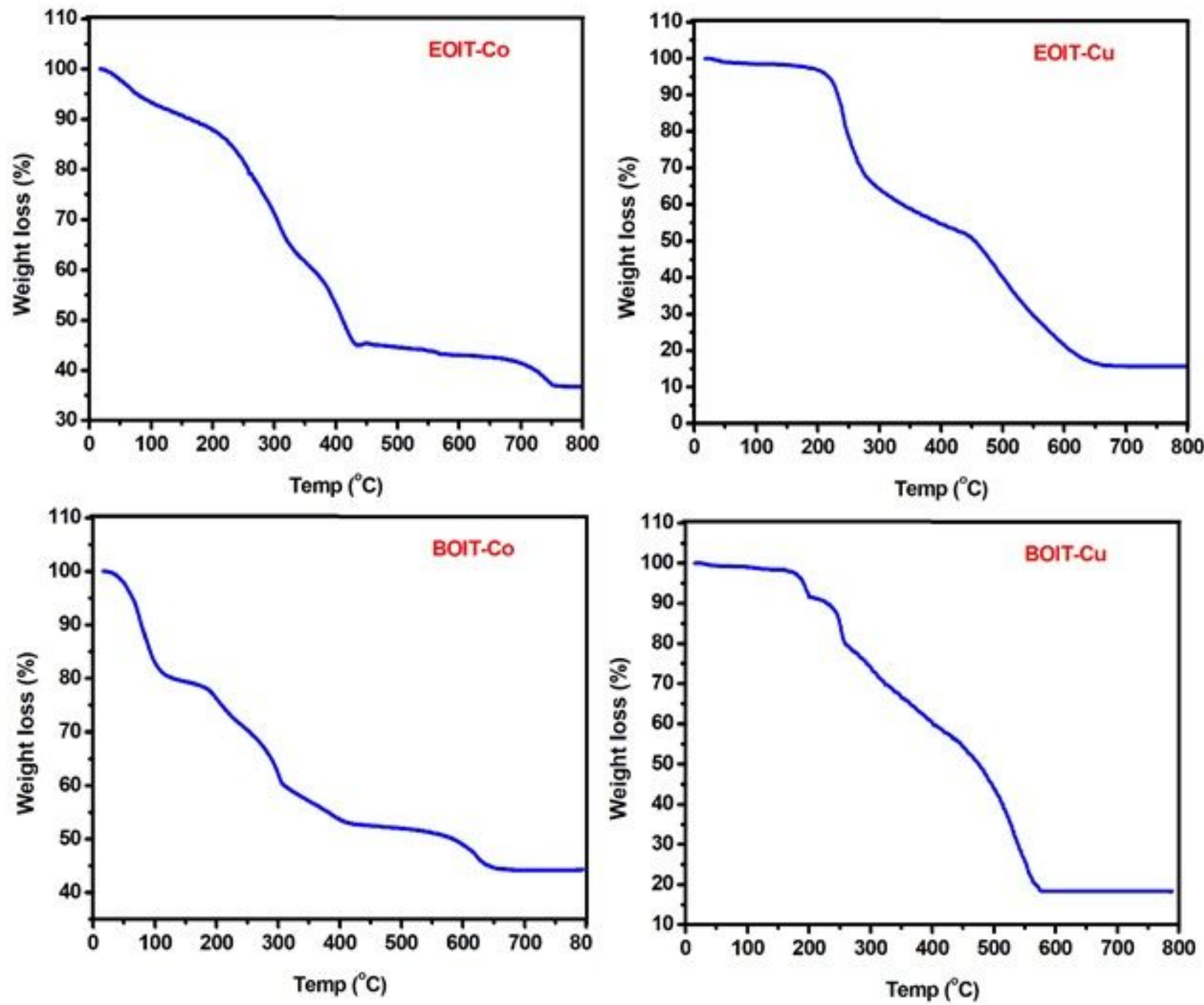

Figure 4

TG thermograms of the metal complexes
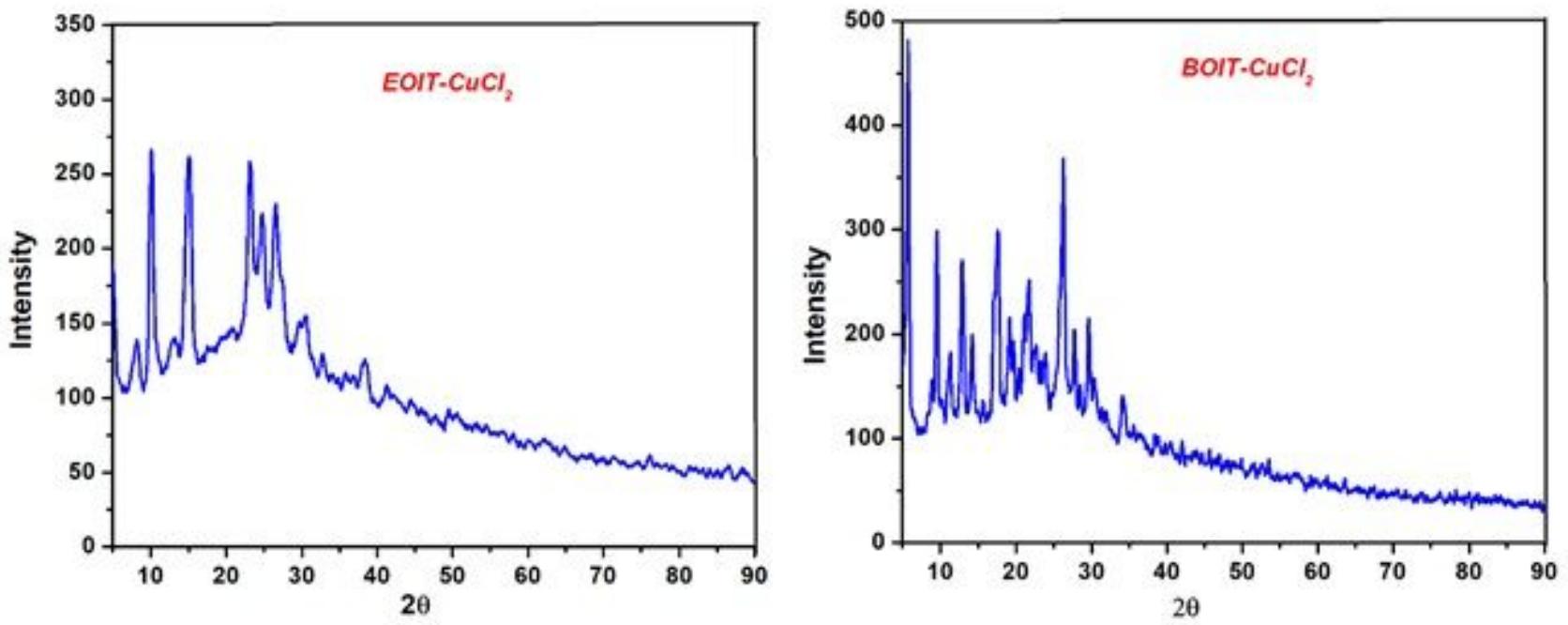

Figure 5 
The XRD for the two complexes EOIT-CuCl2 (a) and BOIT-CuCl2 (b)

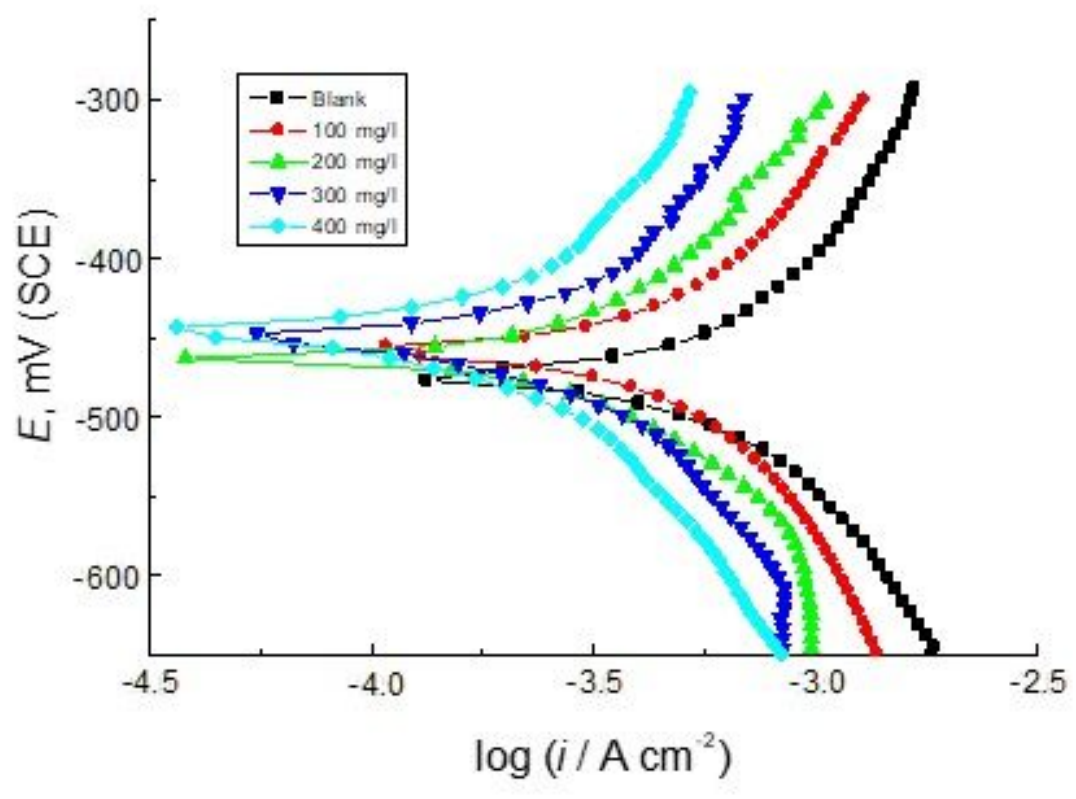

Figure 6

Potentiodynamic polarization curves of in the corrosion of Sabic iron in $1.0 \mathrm{M} \mathrm{HCl}$ solution without and with various concentrations of EOIT-Co complex at $298 \mathrm{~K}$. 

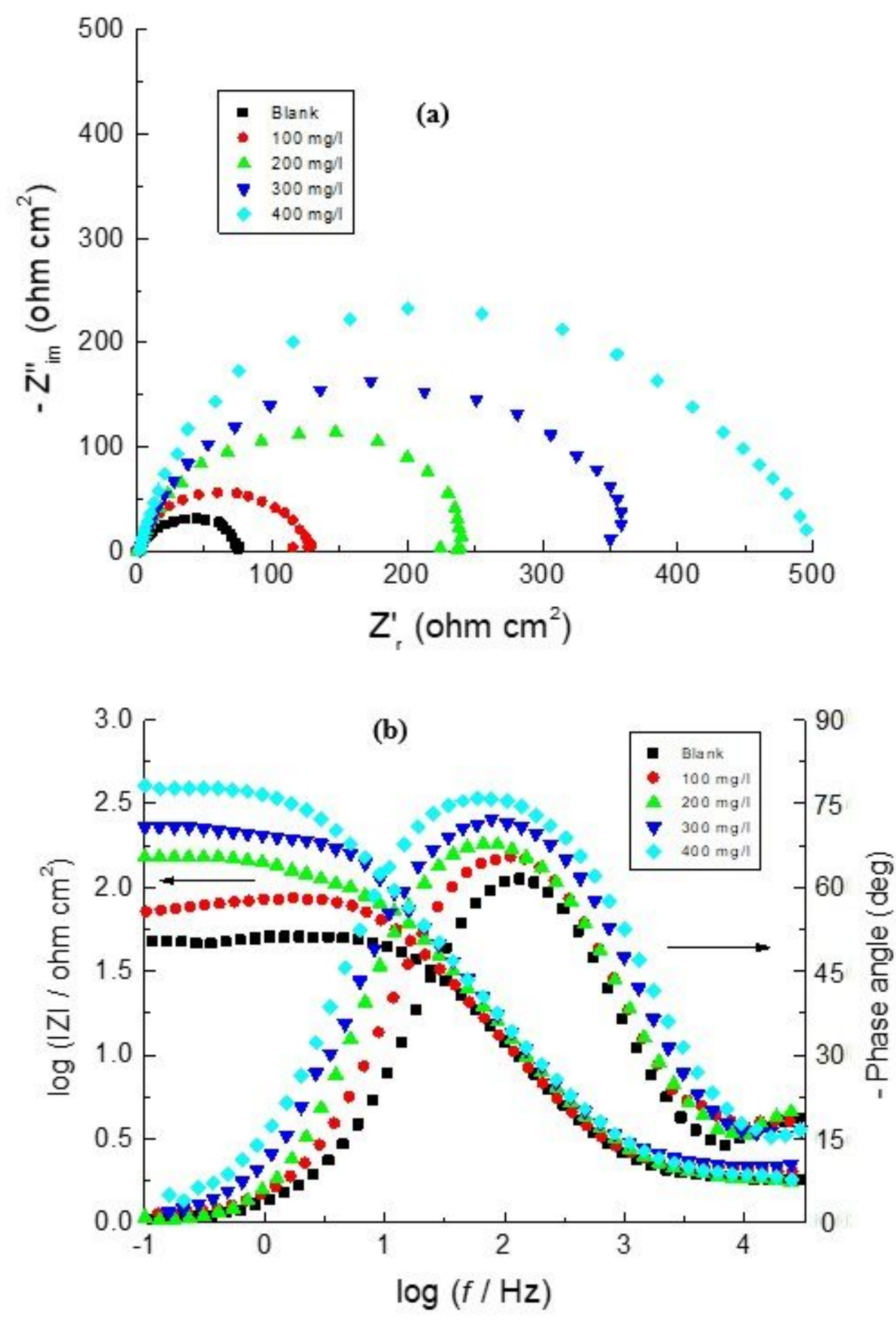

Figure 7

a) Nyquist plot and b) Bode plots (magnitude and phase) for the corrosion of Sabic iron corrosion in 1.0 $\mathrm{M} \mathrm{HCl}$ solution in absence and existence of various concentrations of EOIT-Cu complex at $298 \mathrm{~K}$. 


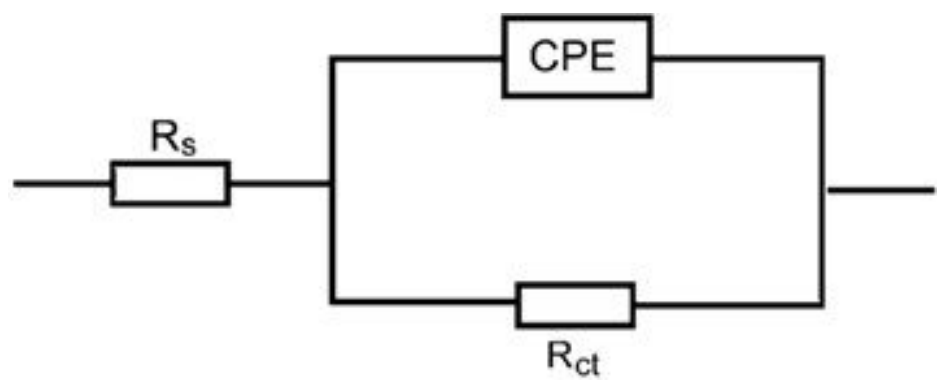

Figure 8

Electrochemical equivalent circuit used to fit the EIS output data for Sabic iron in $1.0 \mathrm{M} \mathrm{HCl}$ solution without and with the investigated compounds.

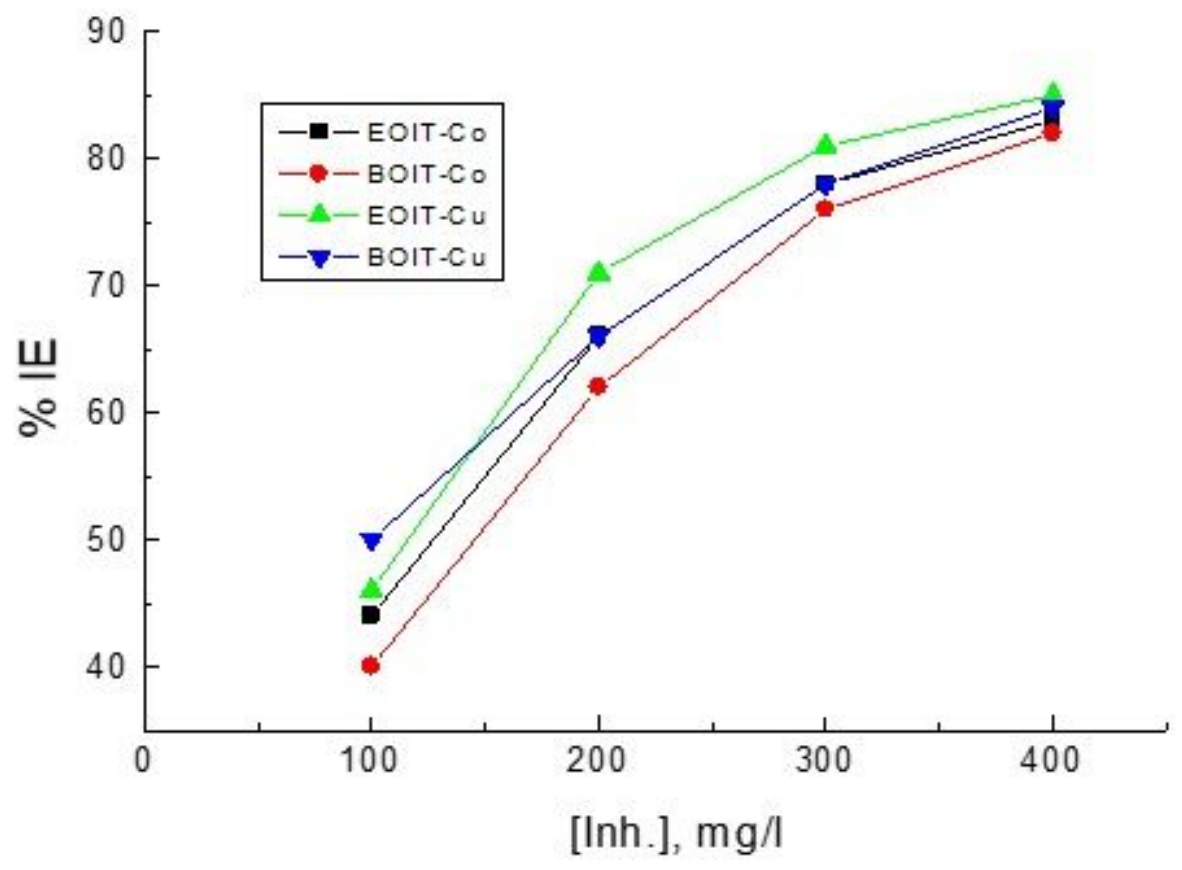

Figure 9

Variation of inhibition efficiencies with the concentrations of the investigated compounds obtained from the impedance results for the corrosion of Sabic iron in $1.0 \mathrm{M} \mathrm{HCl}$ at $298 \mathrm{~K}$. 


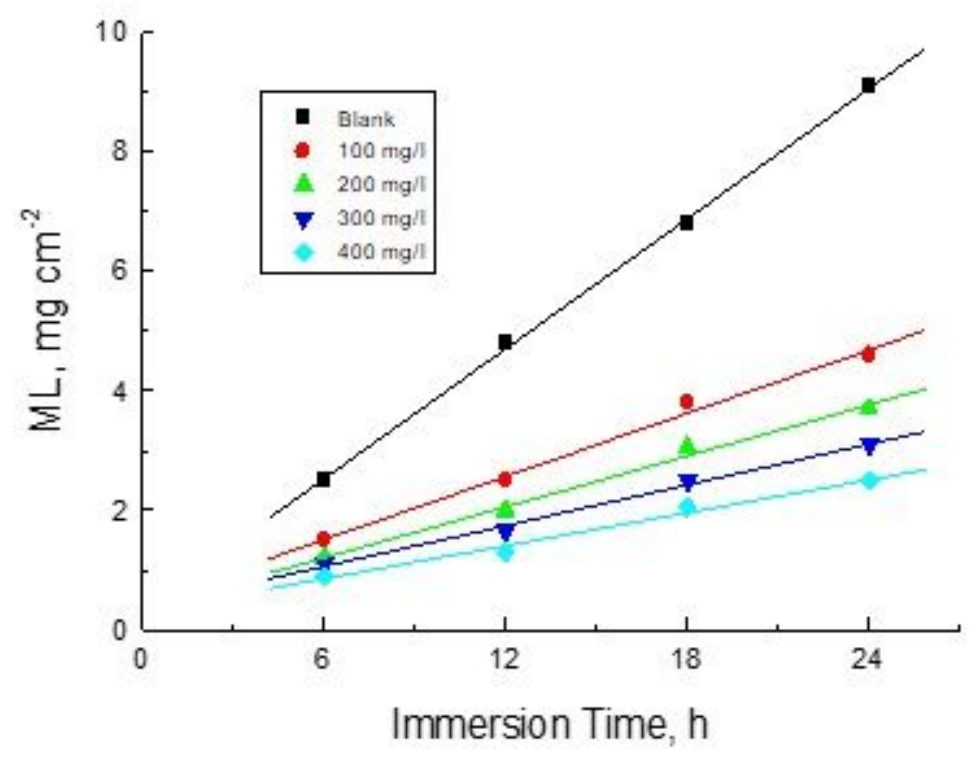

Figure 10

Mass loss (ML) versus immersion time in the corrosion of Sabic iron in $1.0 \mathrm{M} \mathrm{HCl}$ solution in the absence and presence of various concentrations of BOIT-Co complex at $298 \mathrm{~K}$.

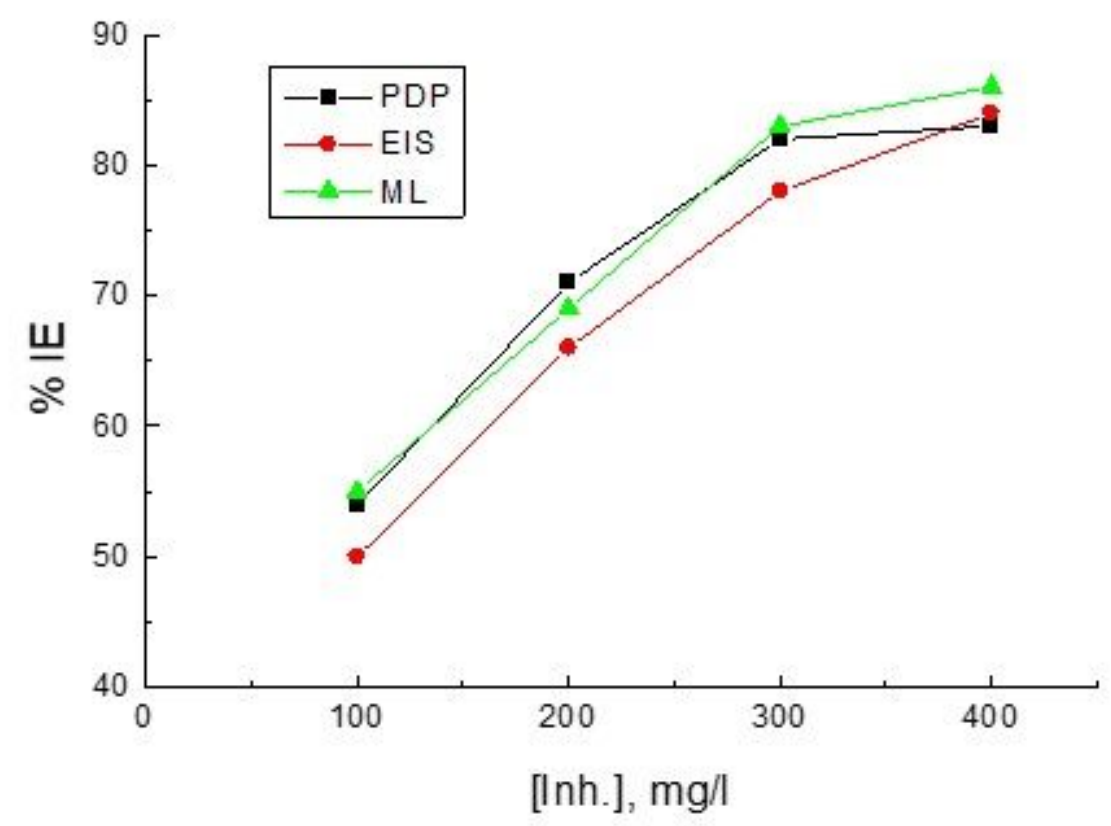

\section{Figure 11}

Variation of the \%IEs of the complex BOIT-Cu with its concentration obtained from PDP, EIS and ML measurements, in the corrosion of Sabic iron in $1.0 \mathrm{M} \mathrm{HCl}$ solution at $298 \mathrm{~K}$. 


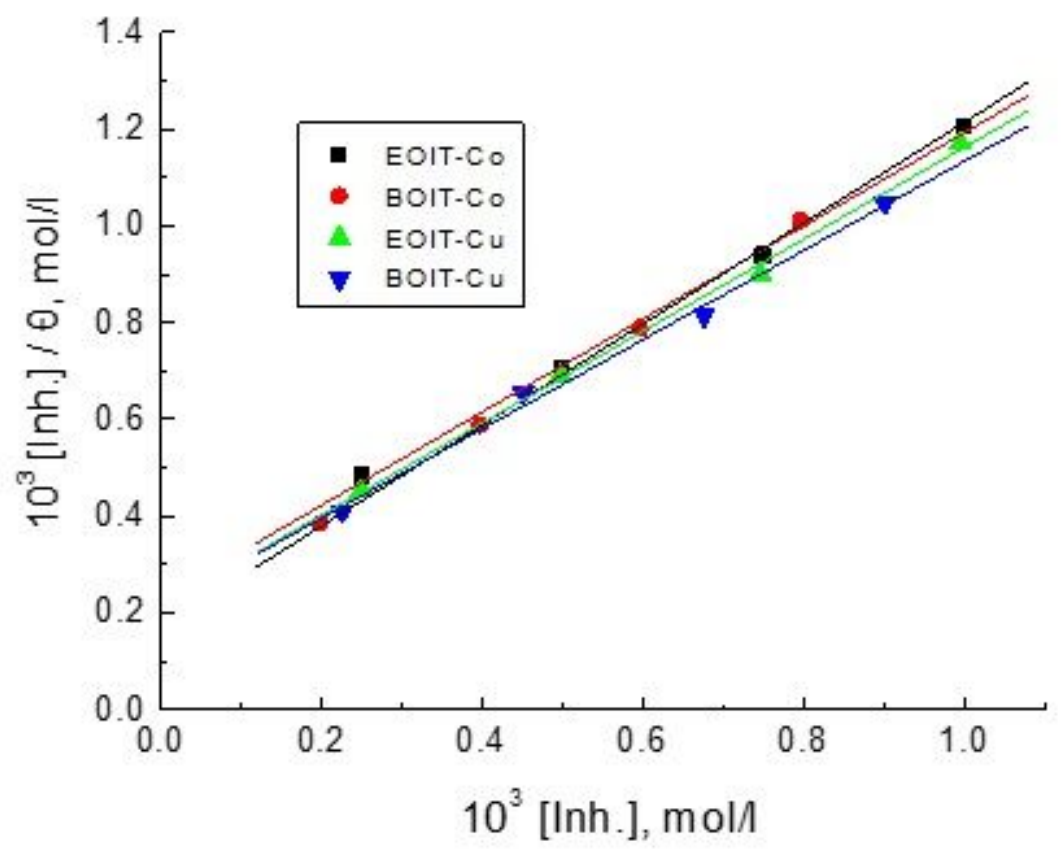

Figure 12

Langmuir adsorption isotherms for the investigated compounds adsorbed on the surface of Sabis iron in $1.0 \mathrm{M} \mathrm{HCl}$ solution at $298 \mathrm{~K}$. 

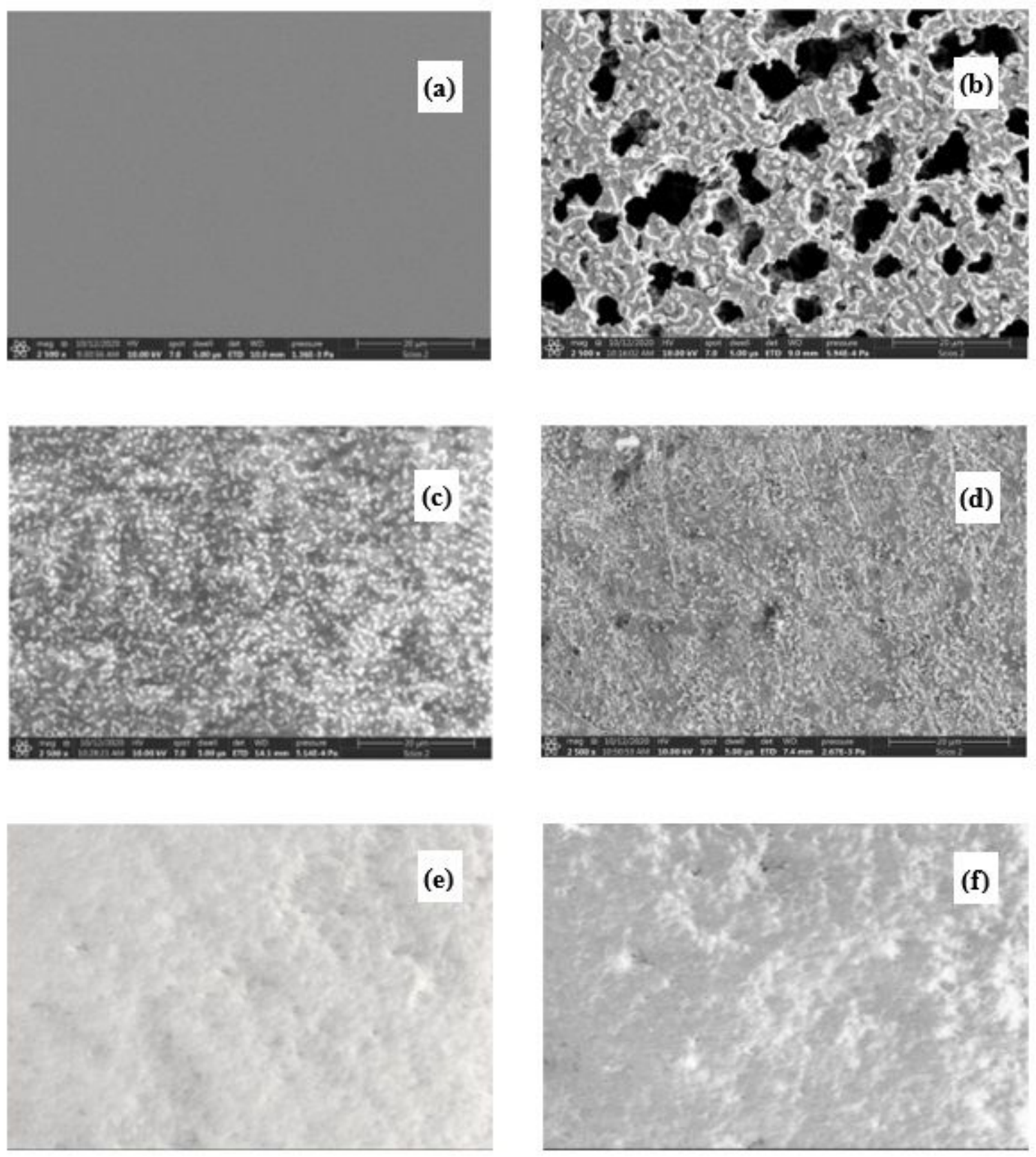

Figure 13

SEM images for Sabic iron surfaces: (a) before dipping in the corrosive solution (1.0 M HCl), (b) after $24 \mathrm{~h}$ dipping in $1.0 \mathrm{M} \mathrm{HCl},(\mathrm{c}),(\mathrm{d}),(\mathrm{e})$ and (f) after $24 \mathrm{~h}$ dipping in the corrosive media involving $200 \mathrm{mg} / \mathrm{l}$ of the synthesized complexes: EOIT-Co, BOIT-Co, BOIT-Cu and EOIT-Cu, successively, at $298 \mathrm{~K}$.

\section{Supplementary Files}

This is a list of supplementary files associated with this preprint. Click to download.

- Schemes.pdf 